OPEN ACCESS

Edited by:

Rajko Reliic,

St George's, University of London, United Kingdom

Reviewed by:

Arun Kumar

Linköping University, Sweden Giampiero Pietrocola,

University of Pavia, Italy

*Correspondence:

Maurizio Fraziano fraziano@bio.uniroma2.it

Specialty section:

This article was submitted to Vaccines and Molecular Therapeutics,

a section of the journal

Frontiers in Immunology

Received: 28 November 2017

Accepted: 17 January 2018

Published: 05 February 2018

Citation:

Nisini R, Poerio N, Mariotti S, De Santis F and Fraziano M (2018)

The Multirole of Liposomes in

Therapy and Prevention of

Infectious Diseases.

Front. Immunol. 9:155.

doi: $10.3389 /$ fimmu.2018.00155

\section{The Multirole of Liposomes in Therapy and Prevention of Infectious Diseases}

\author{
Roberto Nisini', Noemi Poerio ${ }^{2}$, Sabrina Mariotti ${ }^{1}$, Federica De Santis ${ }^{2}$ and \\ Maurizio Fraziano ${ }^{2 *}$
}

${ }^{1}$ Dipartimento di Malattie Infettive, Istituto Superiore di Sanità, Rome, Italy, ${ }^{2}$ Dipartimento di Biologia, Università degli Studi di Roma "Tor Vergata", Rome, Italy

Liposomes are closed bilayer structures spontaneously formed by hydrated phospholipids that are widely used as efficient delivery systems for drugs or antigens, due to their capability to encapsulate bioactive hydrophilic, amphipathic, and lipophilic molecules into inner water phase or within lipid leaflets. The efficacy of liposomes as drug or antigen carriers has been improved in the last years to ameliorate pharmacokinetics and capacity to release their cargo in selected target organs or cells. Moreover, different formulations and variations in liposome composition have been often proposed to include immunostimulatory molecules, ligands for specific receptors, or stimuli responsive compounds. Intriguingly, independent research has unveiled the capacity of several phospholipids to play critical roles as intracellular messengers in modulating both innate and adaptive immune responses through various mechanisms, including (i) activation of different antimicrobial enzymatic pathways, (ii) driving the fusion-fission events between endosomes with direct consequences to phagosome maturation and/or to antigen presentation pathway, and (iii) modulation of the inflammatory response. These features can be exploited by including selected bioactive phospholipids in the bilayer scaffold of liposomes. This would represent an important step forward since drug or antigen carrying liposomes could be engineered to simultaneously activate different signal transduction pathways and target specific cells or tissues to induce antigen-specific $\mathrm{T}$ and/or B cell response. This lipid-based host-directed strategy can provide a focused antimicrobial innate and adaptive immune response against specific pathogens and offer a novel prophylactic or therapeutic option against chronic, recurrent, or drug-resistant infections.

Keywords: liposome, infectious disease, therapy, immunotherapy, drug, vaccine, adjuvant, immunomodulation

\section{INTRODUCTION}

Liposomes are small artificial spherical vesicles constituted by one or more phospholipid bilayers with the polar groups of phospholipids oriented to the inner and outer aqueous phase. Such a structure explains the high propensity of liposomes to be encapsulated with hydrophilic, hydrophobic, and amphiphilic drugs within the inner aqueous compartment, the lipid bilayers, and at their interfaces, respectively (1). Liposomes can be classified as unilamellar (ULV) or multilamellar (MLV) vesicles (2), depending on the structure of the bilayer (Figure 1). ULV are characterized by the presence of a 


\section{A} Unilamellar vesicles (ULV)

\section{0-250 $\mathrm{nm}$ diameter}

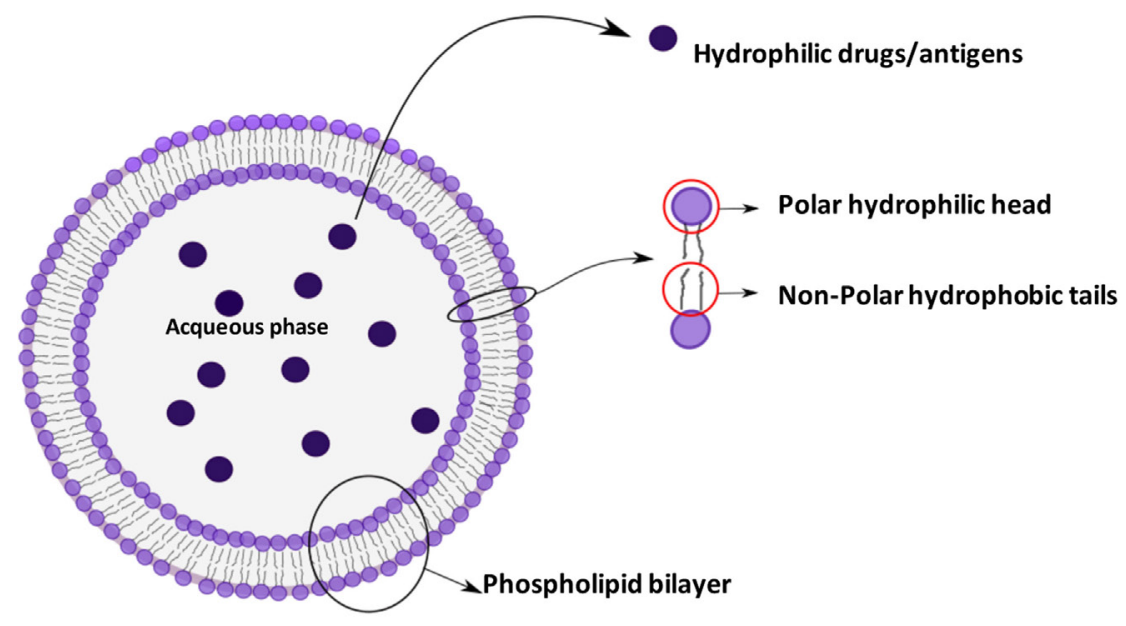

B

Multilamellar vesicles (MLV) 1-5 $\mu \mathrm{m}$ diameter

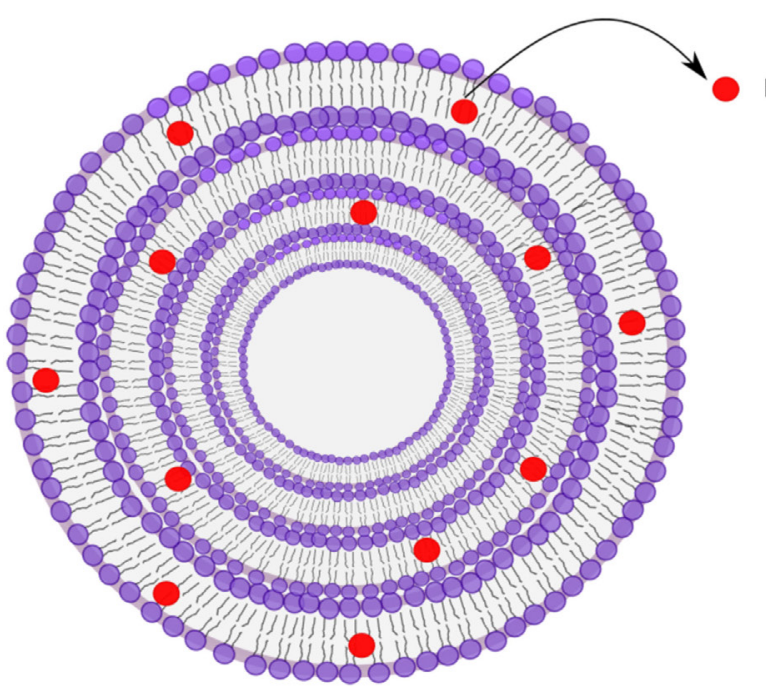

Hydrophobic drugs/antigens

FIGURE 1 | Schematic representation of liposomes showing the different antigen encapsulation propensity: unilamellar (A) and multilamellar (B) vesicles.

single-lipid bilayer of 20-250 nm diameter, which enclose a large aqueous core and are ideally suited for the encapsulation of hydrophilic drugs/antigens (2). Conversely, MLV are characterized by the presence of two or more concentric lipid bilayers of $1-5 \mu \mathrm{m}$ diameter that preferentially entrap lipid soluble molecules (2). Liposomes are extensively used as carriers for active molecules in cosmetic and pharmaceutical industries as well as in food and farm industries, where liposomes encapsulation has also been studied to entrap unstable substances such as antioxidants, flavors, and antimicrobials. The phospholipid protective shield forms a barrier, which is normally resistant to the action of enzymes, $\mathrm{pH}$, and free radicals within the body, thus protecting the cargo from degradation until the release occurs at the target cell, organ, or system. Because of the high biocompatibility, biodegradability, low toxicity, and capability to encapsulate hydrophilic and hydrophobic compounds (2), liposomes represent the most successful drug carrier system known to date. Many liposome formulations for the treatment of cancer, fungal, and viral infection as well as pain management are available in clinical use, and many other formulations are being tested in different phases of clinical trials (3). From their first description in 1960s, many liposomes have been produced with distinctive characteristics, which strictly depend on the nature of lipid components, on their possible chemical modifications, and on their surface charge. In particular, early conventional liposomes were mainly constituted by natural phospholipids such as phosphatidylcholine (PC), sphyngomielin, and monosyaloganglioside (4). However, this formulation was subjected to several critical issues, such as the instability in 
plasma and short blood circulation half-life, due to their interaction with high- and low-density lipoproteins that resulted in the rapid release of the encapsulated drug into the plasma, and the efficient liposome uptake and removal from circulation by the macrophage system. Moreover, in most cases, negatively charged liposomes have a shorter half-life in the blood than neutral liposomes, and positively charged liposomes are toxic and quickly removed from circulation (5). The addition of cholesterol (Chol) in liposome formulation reduced the permeability of lipid bilayer, increased the liposome stability, and reduced the rapid release of encapsulated bioactive compound (6). The size was also shown to be a crucial determinant for circulation half-life of liposomes, as their elimination by phagocytes is directly correlated to the liposome diameter: MLV with diameters ranging from 500 to $5,000 \mathrm{~nm}$ are quickly removed by phagocytes, whereas ULV with diameters between 20 and $50 \mathrm{~nm}$ show the less propensity to be internalized by macrophages (5), but are characterized by a low volume available for drug entrapment.

Improvement of liposome technology involved the generation of stealth liposome, targeted liposomes, immunoliposomes, and stimuli responsive liposomes (Figure 2). The stealth strategy is based on the possibility to coat the external liposome surface with biocompatible hydrophilic polymer conjugates, such as polyethylene glycol (PEG), chitosan, and others, which reduces immunogenicity and macrophage uptake. Stealth liposome technology makes liposome capable to escape phagocytosis, to reduce toxicity due to the presence of charged lipids, and to increase blood circulation half-life. However, an important limitation of stealth liposomes is their large biodistribution in tissues, as encapsulated bioactive molecules cannot be selectively delivered to target cells (7). Targeted liposomes where therefore designed to counterbalance the large body distribution of stealth liposomes. Targeted liposomes are characterized by the presence of membranes functionalized with glycoproteins, polysaccharides, or ligands for specific receptors that determine the preferential accumulation of liposomes in selected tissues, so that the liposome drug/antigen cargo can be preferentially released in predetermined target cells or organs (7). A further strategy to deliver entrapped drug/antigen in the desired tissue/cell is represented by immunoliposomes, which are functionalized by antibodies or antibody fragments (8), and stimuli responsive liposomes. Examples of stimuli responsive liposomes are the $\mathrm{pH}$-sensitive liposomes (9), which undergo conformational and chemical changes in response to acid $\mathrm{pH}$, and temperature sensitive liposomes (10), which keep their cargo encapsulated at body temperature, but discharge it upon local heating.

In addition to the delivery of drugs, liposomes may also be used for many other purposes through the modification of their composition and cargo. In vaccinology, for example, liposomes can be formulated with the inclusion of antigens (lipids, nucleic acids, proteins, and peptides), and/or with pathogen-associated molecular patterns (PAMPs), which confer adjuvant properties aimed at modulating the inflammatory microenvironment where T lymphocyte priming occurs $(11,12)$. At the moment, a number of liposome formulations are in clinical trials as adjuvant for prophylactic as well as therapeutic vaccines against malaria, influenza, tuberculosis (TB), human immunodeficiency virus

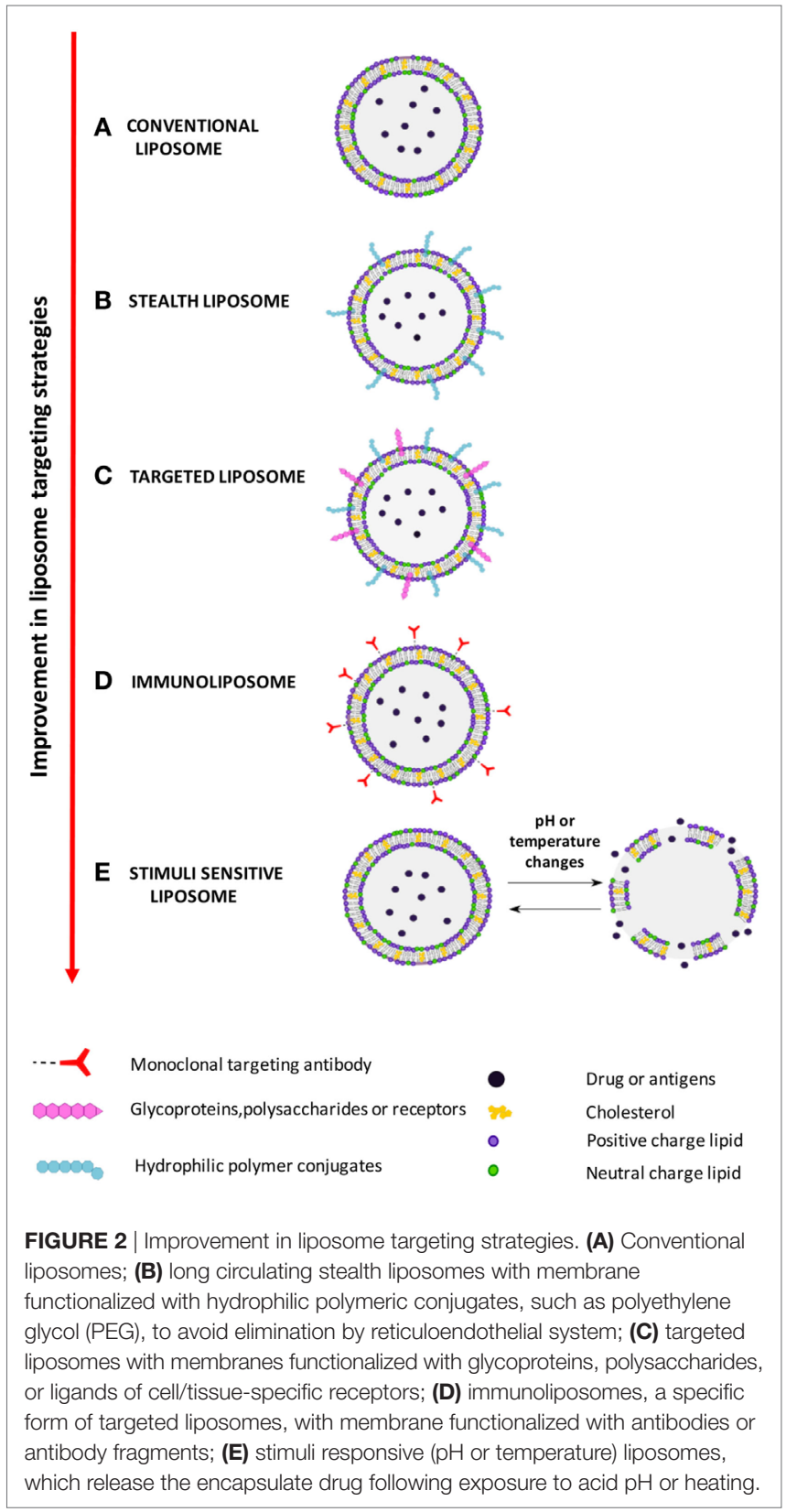

(HIV), and dengue fever (13), whereas Cervarix ${ }^{\circledR}$, Inflexal ${ }^{\circledR}$, and Epaxal $^{\circledR}$ are commercially available liposome vaccines against infection by human papilloma virus (HPV), influenza virus, and hepatitis A virus, respectively. Finally, lipids are important second messengers in the regulation of molecular pathways associated with phagosome maturation and activation of antimicrobial responses (14). Thus, the possibility exists to deliver selected lipid second messengers into infected cells through targeted liposomes to activate antimicrobial molecular pathways against specific bacterial pathogens (15).

This review summarizes the recent developments in liposome technology aimed at the generation of novel prophylactic as well as therapeutic tools to control infectious diseases. 


\section{LIPOSOMES AS CARRIER FOR DRUGS}

The fate of drugs administered to a living organism varies according to several variables, including distribution, metabolism, and excretion. After a drug enters the systemic circulation, it is not distributed uniformly to the body's tissues due to differences in organ blood perfusion, tissue affinity, local $\mathrm{pH}$, and permeability of cell membrane. Thus, a significant amount of a given drug does not reach the target cell or organ. The consequence of the uneven distribution is a reduced concentration of drug reaching the target cells and the interaction of the drug with bystander targets. Increasing the dose of the drug helps reaching the therapeutic concentration at the target level and also increases the effects of the drug on other cells, concurring to amplify side or adverse events of drug administration. The ratio between the blood concentration at which the drug is effective and the concentration at which the drug becomes toxic is defined therapeutic index (TI): the larger is the TI, the safer is the drug. It has to be further stressed that the ultimate target of drugs is generally an intracellular reaction site and the interaction of drugs with the cellular/bacterial lipid membrane is expected to occur at some point, affecting, sometimes severely, drug bioavailability, and efficacy (16). In the absence of specific mechanisms of intracellular transportation, the chemical nature of the drug dictates the level of entrance into cells. An interesting example is given by the different intracellular accumulation rates observed for four structurally similar quinolones: ciprofloxacin, levofloxacin, garenoxacin, and moxifloxacin (17). Quinolones were shown to exert a condensing effect on the membrane bilayer and the condensing effect differed among the quinolones: even small differences in their chemical structure were shown to influence their lipophilicity, the consequent capacity to cross cell membranes and to accumulate intracellularly, and the eventual antimicrobial effect (18). Thus, the search of innovative approaches to increase drug transport across the cell membrane or to improve the permeability of small molecule, peptide, and/or protein-drugs to access the cytoplasm is a hot field in pharmacology (19).

Within a few years after the first description of "swollen phospholipid systems" by Bangham and colleagues (20), various enclosed phospholipid structures consisting of single bilayers, initially termed "banghaosomes" and then "liposomes" (21), were described (22). The observation that liposomes can entrap drugs made these nanoparticles an interesting tool exploitable as new drug delivery systems $(23,24)$. The observation that the anticancer drug cytosine arabinoside was successfully delivered by liposomes to tumor cells with a significant increase in the survival times of mice affected by L1210 leukemia (25) was one of the first demonstrations of the suitability of liposomes as drug delivery system. Murine L1210 leukemia became "model system" for testing the therapeutic outcomes of anticancer drugs delivered by a large variety of liposome with different characteristics (26). Another advantage thatbecame evident usingliposome-entrapped drugs was the reduction of drug toxicity: drugs entrapped in liposomes are not bioavailable until they are released in target organs. Amphotericin B (AmB) and doxorubicin entrapped in liposomes (26) were extensively studied and the pioneering in vitro and in vivo studies ultimately led to the first clinical trials of liposomal drugs (27). However, the first tested "large ULV" for drug delivery showed their limits and many efforts have been made to design liposomes able to target specific cells and favor drug release for an optimized release rate of entrapped drug from the liposomes. For the optimal therapeutic activity, drugs must be released from liposomes to the disease site, where they should become bioavailable at a concentration within their therapeutic window for a sufficient time (26). One of the first obstacles that appeared clear when using large ULV was the rapid clearance of liposomes operated by the phagocyte system in the liver and spleen. Several approaches were tested, ranging from variation in liposome dimension to treatment of liposomes with serum albumin or variation in bilayer composition and Chol content (26). A significant step forward in the field of drug delivered by liposomes was made thanks to the observation that attaching PEG to proteins causes an increase of their circulation half-life (28). When the procedure was applied to the liposome system, it was evident that grafting of PEG to the liposome surface resulted in diminished clearance of liposomes by macrophages (29) and, the PEG-liposomes (stealth liposomes), unlike previously tested ULV, were shown to have dose-independent pharmacokinetics (30). The improvements in the therapeutic outcomes of stealth liposomes in comparison with conventional ULV for a variety of therapeutics was demonstrated in different animal models of disease (26), and then in the humans, where the long circulation half-life of a doxorubicin entrapped in PEG-liposomes was confirmed. Shortly thereafter, doxorubicin entrapped in stealth liposomes was used in the first clinical trial for the treatment of Kaposi's sarcoma in HIV patients (31). The persistence of stealth liposomes in the circulation facilitated their accumulation in highly vascularized sites, such as tumors or inflammatory sites. However, it appeared clear that both the efficacy and the TI would increase if drug-bearing liposomes could be selectively addressed to target cells.

Active targeting could be accomplished by coupling targeting ligands to the surface of liposomes, such as proteins, peptides, carbohydrates, or monoclonal antibodies or their fragments (fragment antigen-binding and single-chain variable fragment) (32). Thus, targeted liposomes can be selectively taken up by cells that overexpress the receptor for the moiety, so improving therapeutic outcomes by increasing efficacy and reducing off-target toxicity (32). Among the different moieties that can be covalently or non-covalently attached to the liposome surface, antibodies and antibody fragments are the most widely employed, producing immunoliposomes (33). Spragg and coworkers demonstrated that E-selectin-targeted immunoliposomes for doxorubicin delivery mediated marked cytotoxicity when incubated with activated human umbilical vein endothelial cells (HUVECs) that express E-selectin, but not when incubated with non-activated HUVECs (34). Following these promising results, methods for antibody coupling to liposomes have been developed (33) and different antibodies or fragments have been attached to liposomes, particularly through reactions with maleimide. Examples include immunoliposomes targeted to soluble Leishmania antigens, EFGR for glioma, endoglin (CD105), fibroblast activation protein, and HER2 for breast cancer, among others (35-38). 
In addition to the possible systemic use, i.e., intravenous administration (39), liposomes have been designed for aerosol administration (40) or intradermal administration due to their lipophilic properties suitable for skin penetration (41). The functionalization of liposomes makes it possible to design drug delivery systems suitable for the treatment of different diseases according to their pathogenesis and localization. Among other diseases, liposomes have been primarily and deeply studied for cancer treatment. The narrow TI of antitumor drugs, i.e., the narrow window between their effective doses and those at which they produce adverse toxic effects, makes liposomes as ideal carriers for this type of drugs (42). Indeed, the majority of liposome-delivered drugs available for clinical use (Table 1) and in advanced phase III studies to date belongs to this category (3).

The property of encapsulation of drugs in liposomes to enhance the TI of various agents was the reason for the first use of anti-infectious drugs in severely ill patients with renal failure. To date, the only drug delivered by liposomes approved for clinical use in the field of infectious disease is AmB, but many studies are ongoing aimed at taking advantage of this versatile platform to treat patients with a variety of different infectious diseases. Three formulations of $\mathrm{AmB}$ for parenteral use were made available differing for liposome formulation and indications. Abelcet ${ }^{\circledR}$ was developed in 1995 for the treatment of invasive fungal infections refractory to conventional $\mathrm{AmB}$ desoxycholate therapy or when renal impairment or unacceptable toxicity precludes the use of conventional AmB (3). Abelcet ${ }^{\circledR}$ has a 1:1 drug:lipid molar ratio with a drug concentration ranging from 25 to about $50 \%$ molar (49). Ambisome ${ }^{\circledR}$ was approved in 1997 for the treatment of severe fungal infections including leishmaniasis, aspergillosis, blastomycosis, coccidioidomycosis in febrile, neutropenic patients, and a severe form of meningitis in individuals infected with HIV (3). Ambisome ${ }^{\circledR}$ is also indicated for the treatment of invasive systemic infections caused by Aspergillus sp., Candida sp., or Cryptococcus sp. in renal impaired patients or in patients who cannot tolerate therapy with free $\mathrm{AmB}$ (50). Amphotec ${ }^{\circledR}$ is a freeze-dried lipid-based formulation of AmB. The sodium salt of cholesteryl sulfate forms a thermodynamically stable colloidal complex with AmB at a 1:1 drug-to-lipid molar ratio (3).

In the field of parasitic infections, several studies were performed to test the efficacy of liposome-encapsulated drugs. In the treatment of leishmaniosis, an interesting approach is based on the use of dinitroanilines, because of their specific binding to parasite but not human tubulins. However, their low water solubility and instability have blocked their development as antiparasitic agents (51). Encapsulation of drug by dimyristoyl PC- and dimyristoyl phosphatidylglycerol-based liposomes overcome those limitations and allowed to efficiently deliver the drugs, reaching a therapeutic advantage as demonstrated in animal models (51). Another drug under test for liposome delivery is buparvaquone, an extensively studied drug for the treatment of visceral leishmaniosis. da Costa-Silva et al. reported that buparvaquone, which has an immunomodulatory effect in host cells, when entrapped in phosphatidylserine (PS) exposingliposomes, as a delivery approach to macrophage, is highly effective at low doses at eliminating Leishmania infantum parasites in a hamster model (52).

In the fight against malaria, the majority of drugs under development are lipophilic and characterized by poor plasma solubility and large biodistribution volumes with low accumulation in red blood cells (RBC). As a consequence, these drugs have shown limited therapeutic activity against intra-erythrocyte plasmodia (53). Rajendran et al. developed lipid formulations of soy-PC Chol containing either stearylamine (SA) or phosphatidic acid (PA) and different densities of distearoyl phosphatidylethanolamine-methoxy-PEG 2000 as a delivery system to test the antimalarial activity of monensin. Monensin entrapped in such liposome formulations was tested both in in vitro systems of Plasmodium falciparum cultures and in in vivo murine models of Plasmodium berghei infection and found to be more effective than free monensin given at comparable doses (54). The trans platinum-chloroquine diphosphate dichloride was recently successfully tested after its encapsulation into PEGylated neutral and cationic liposomes to fight parasites resistant to traditional drugs and proposed as a new therapeutic tool against malaria (55). Preliminary assays conducted in 1987 using passively loaded chloroquine into RBC-targeted immunoliposomes resulted in significant $P$. berghei growth inhibition in mice, when compared with administration of the free compound (56). More recently, the immunoliposome strategy against malaria was tested taking advantage of a monoclonal antibody specific for a $52-\mathrm{kDa} \mathrm{RBC}$ surface antigen characteristic of the murine erythroid lineage

TABLE 1 | Liposome-delivered drugs in clinical use for the treatment of tumor.

\begin{tabular}{|c|c|c|c|}
\hline Commercial name & Drug & Liposome composition & Indications \\
\hline DaunoXome ${ }^{\circledR}$ & Daunorubicin & Small size liposome & HIV-associated Kaposi's sarcoma (44) \\
\hline Depocyt $^{\oplus}$ & Cytarabine/Ara-C & $\begin{array}{l}\text { Multivesicular particles with a granular } \\
\text { structure: DepoFoam }{ }^{\mathrm{TM}}\end{array}$ & Neoplastic meningitis (45) \\
\hline Mepact ${ }^{\circledR}$ & $\begin{array}{l}\text { Mifamurtide: } \\
\text { immunostimulant } \\
\text { muramyltripeptide }\end{array}$ & Multilamellar vesicles & $\begin{array}{l}\text { High-grade, resectable, non-metastatic bone tumors combined with } \\
\text { postoperative combination chemotherapy in children (46) }\end{array}$ \\
\hline Marqibo ${ }^{\circledR}$ & Vincristine & $\begin{array}{l}\text { Optisomes: sphingomyelin/cholesterol } \\
\text { liposome }\end{array}$ & $\begin{array}{l}\text { Adult patients with Philadelphia chromosome-negative acute lymphoblastic } \\
\text { leukemia (47) }\end{array}$ \\
\hline Onivyde ${ }^{\mathrm{TM}}$ & Irinotecan & Multilamellar vesicles & Metastatic adenocarcinoma of the pancreas (48) \\
\hline
\end{tabular}


and specifically expressed from the early proerythroblast to mature RBC stages. These immunoliposomes loaded with two novel antimalarial lipophilic drug candidates in the mouse model of Plasmodium yoelii increased the TI and efficacy of the used drug (53). Liposomes exposing PS-specific peptide may represent a further strategy to target plasmodia infected RBC in apoptosis (eryptosis:erythrocyte apoptosis) that have been tested in malaria treatment, with promising results (57). Experimental malaria may also represent a model to study the combined effect of anti-infective drugs and anti-inflammatory compounds aimed to limit immunopathogenic reactions in critical anatomic sites, such as the brain. Guo et al. tested liposome-encapsulated $\beta$-methasone hemisuccinate in a murine model of experimental cerebral malaria and found that this antiinflammatory liposome-delivered drug prolonged the survival time of infected animals, permitting the administration of antimalarial drug before the development of severe anemia (58). In addition to malaria, liposomes, as part of nanopharmaceuticals, are promising tools under investigation for the treatment of several other parasitic diseases including schistosomiasis (59, $60)$ and acanthamoebiasis (61), which are grouped under the term of neglected diseases (62).

In 2016, it was estimated that there were nine million new TB cases in the world and around half a million of them were caused by multidrug-resistant (MDR) Mycobacterium tuberculosis (Mtb) strains (Global tuberculosis Report 2017. http://www. who.int/tb/publications/global_report/en/ Health Organization, Geneva, Switzerland). The research is focused in developing new antimicrobials, but the need to reach a sufficiently high drug concentration inside the lung macrophages and the appearance of MDR and extensively drug-resistant (XDR) Mtb strains represent two major obstacles to reach this goal $(63,64)$. A possible strategy to the development of new anti-TB therapeutics is based on the administration of drugs contained in specific nanodevices (62), which, preferentially targeting macrophages, allows the use of lower drug dosage and the reduction of undesirable side effects as well as the limitation of Mtb resistance mechanisms. In this line, an interesting contribution to the development of innovative anti-TB therapeutic strategies is the inhalation therapy with liposomes carrying anti-TB drugs. The inhaled drug is expected to be rather effective in the overt presence of bacteria as in smear-positive cases of TB in which the bronchial tree may be directly connected with the cavitary lesions, where Mtb rapidly multiplies. Liposomes delivering anti-TB drugs may offer several advantages over dry powder inhalable formulations of anti-TB drug $(65,66)$ or other aerosol administrable nanoparticles $(67)$, such as the increase of drug half-life and the possibility to target the intracellular pathogen (68). However, difficulties may arise to efficiently entrap some of the drugs required for TB treatment into liposomes. Justo and Moraes showed that passive encapsulation of isoniazid and pyrazinamide in liposomes during dry lipid film hydration at initial drug-to-lipid molar ratios of 13.3 can be achieved with efficiencies of 2.5 and of $2.2 \%$, respectively, equivalent to final drug-to-lipid molar ratios of 0.33 and 0.29 (69). Moreover, they were also able to incorporate ethionamide during the dry lipid film production step with a $42 \%$ trapping efficiency, equivalent to a low final drug-to-lipid molar ratio of
0.04 (69). Justo and Moraes were unable to efficiently incorporate rifampicin and streptomycin in the vesicles under the conditions tested. In contrast, Zaru et al. succeeded in entrap rifampicin in liposomes made of phospholipon $90^{\circledR}$, soy lecithin, and Chol using the film hydration method followed by procedures of freeze dry (70). A deeper deposition of rifampicin entrapped in these liposomes in comparison with rifampicin suspension was found in lung airways of rats after nebulization of a nose-only exposure chamber, encouraging the use of liposomes in aerosol therapy of TB (71). An additional aspect to be faced is the stability of liposome-entrapped drugs. Stability may be enhanced by the use of pro-liposomes, i.e., free flowing granular products composed of drug and phospholipid precursors, which on hydration lead to liposomes $(72,73)$ that have a higher stability upon reconstitution. A new single-step and fast spray drying technique for pro-liposome powder preparation was developed $(74,75)$ using a systematic method known as "Quality by Design" (71): a systematic approach to develop drug products that includes evaluation of formulation parameters to achieve defined final product quality (76). The method was used to prepare rifapentine-loaded pro-liposomes, which resulted in an average size of $578 \mathrm{~nm}$ and an efficiency of encapsulation around 70\% (71). The proliposome with a drug/hydrogenated soy-PC ratio of 1:2 and SA as a charge-inducing agent $(74,75)$ are promising formulations and represent possible new tools to approach therapy of infectious diseases based on the optimization of the delivery of old drugs. However, liposomes may be also considered for the delivery of new developed drugs to reduce or delay the appearance of drug resistance.

Liposome-entrapped drugs or immunomodulating agents are being developed for the treatment of many other diseases (see some examples in Table 2). However, clinical trials based on innovative liposome strategies should take into account also possible side effects that these drug formulations may have, particularly when given intravenously, and the fulfillment of several regulatory landscape. Both FDA and EMA have developed specific guidelines to be fulfilled in clinical trials with reference to future novel liposomal products $(77,78)$.

TABLE 2 | Possible applications of liposome-encapsulated drug.

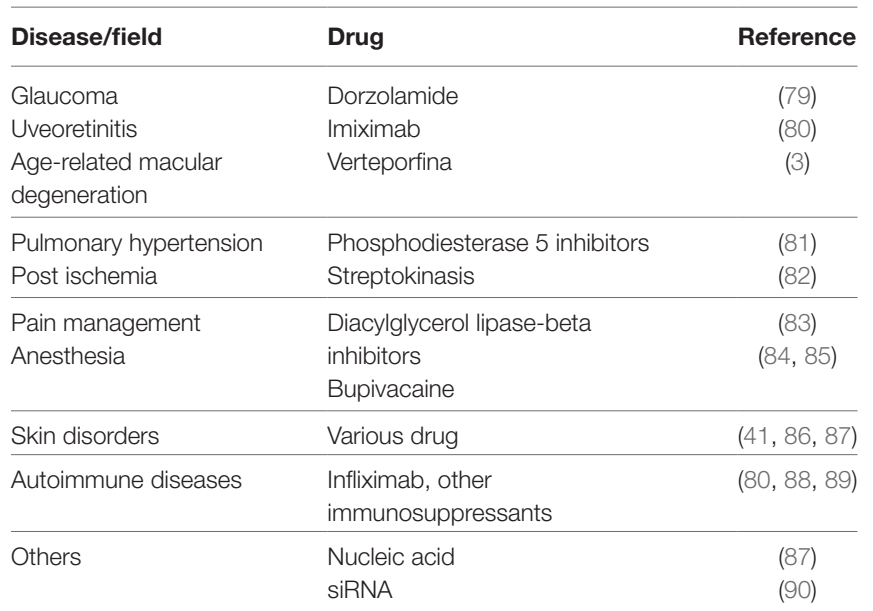




\section{LIPOSOMES AS "DIRECT" ENHANCERS OF INNATE ANTIMICROBIAL IMMUNE RESPONSE}

For long time, the function of lipids was believed to be limited to their role as structural components of membranes or principal form of energy storage in cells. However, during the past 30 years, their important role in cell physiology has been disclosed and lipids have been identified as fundamental players in many cellular functions, including, among others, the regulation of signaling, organization of membranes, intracellular vesicle trafficking, and phagocytosis. Particularly interesting is the role of lipids in the physiology and pathology of phagocytosis, which represents a critical step in the effector function of innate immunity. In fact, the phagosome formation and maturation are functions involving coordinated signaling, targeting, and trafficking events largely regulated by lipid moieties $(91,92)$. In this process, several lipid species accumulate in membrane microdomains, where they associate in signaling transduction platforms (93). In addition, several lipids can (i) promote positive (convex) or negative (concave) membrane curvature, (ii) recruit signal proteins by binding to specific lipid-binding domains (Table 3), and (iii) confer an electrostatic potential on membrane to attract opposite charged key signaling and effector proteins (91-93). Thus, intracellular vesicle trafficking is finely regulated by a topologically and temporally controlled lipid expression whose main role, in the case of phagocytosis, is to promote the fusion/fission events, which starting from phagosomes leads to the generation of a bactericidal phagolysosome (PL) (14). Phagocytosis starts with particle recognition by phagocytic receptors and proceeds with phagocytic cup formation, phagosome sealing (PSL), and internalization (Figure 3A). In particular, one of the first events occurring during phagocytic receptor signaling is a local rapid accumulation of phosphatidylinositol (PI) 4,5-bis phosphate [PI $\left.(4,5) \mathrm{P}_{2}\right](94)$, mediated by PI 4-phosphate 5-kinases (PIP5Ks), whose activity both regulates phospholipase $\mathrm{D}(\mathrm{PLD})$ and is regulated by $\mathrm{PA}$, the product of PLD (95). Few minutes after accumulation, PI $(4,5) \mathrm{P}_{2}$ is rapidly degraded by phospholipase $\mathrm{C} \gamma$ (PLC $\gamma$ ) or phosphorylated, by type I phosphoinositide 3-kinase (PI3K), to PI $(3,4,5)$ $\mathrm{P}_{3}$ (96), whose formation is required for pseudopod extension and phagosome formation (97). The rise of $\mathrm{PI}(3,4,5) \mathrm{P}_{3}$ at sites of phagocytic receptor engagement promotes the recruitment of PLC $\gamma$ through its pleckstrin homology (PH) domain (98), with the consequent hydrolysis of $\mathrm{PI}(4,5) \mathrm{P}_{2}$ to diacylglycerol (DAG), which in turn can be converted in PA by DAG kinases (99). PA, $\mathrm{PI}(4,5) \mathrm{P}_{2}$, and $\mathrm{PI}(3,4,5) \mathrm{P}_{3}$ represent the most important lipid second messengers involved in the early phases of phagocytosis. These lipids contribute to the lateral spreading of phagocyte receptor signaling, which is important to integrate the signals elicited by sparsely phagocytic receptors and to cytoskeletal remodeling. Remodeling culminates with the formation of pseudopods, which surrounding the phagocytic target and sealing at their distal tips, form the phagosome (96). Phosphoinositides are key molecules in modulating cytoskeletal reorganization starting from the early phases of phagocytosis: $\mathrm{PI}(3,4,5) \mathrm{P}_{3}$ contributes by recruiting WAVE and myosin $\mathrm{X}$ to forming phagosomes, while
TABLE 3 | Lipid-binding domains and protein interaction of the most representative bioactive lipids involved in phagocytosis process.

\begin{tabular}{|c|c|c|}
\hline Lipid & Binding domains & Reference \\
\hline \multirow[t]{2}{*}{$\mathrm{Pl}(3) \mathrm{P}$} & FYVE & $(106)$ \\
\hline & PX & $(107)$ \\
\hline \multirow[t]{2}{*}{$\mathrm{Pl}(4) \mathrm{P}$} & ENTH & $(108)$ \\
\hline & $\mathrm{PH}$ & (109) \\
\hline $\mathrm{Pl}(5) \mathrm{P}$ & $\mathrm{PHD}$ & $(110)$ \\
\hline \multirow[t]{6}{*}{$\mathrm{PI}(4,5) \mathrm{P}_{2}$} & ENTH & $(111)$ \\
\hline & ANTH & $(112)$ \\
\hline & $\mathrm{PH}$ & (113) \\
\hline & C2 & (114) \\
\hline & FERM & (115) \\
\hline & PTB & $(116)$ \\
\hline \multirow[t]{2}{*}{$\mathrm{PI}(3,5) \mathrm{P}_{2}$} & ENTH & $(117)$ \\
\hline & GRAM & (118) \\
\hline \multirow[t]{2}{*}{$\mathrm{PI}(3,4) \mathrm{P}_{2}$} & PX & (119) \\
\hline & $\mathrm{PH}$ & $(107)$ \\
\hline \multirow[t]{3}{*}{$\mathrm{Pl}(3,4,5) \mathrm{P}_{3}$} & PX & (119) \\
\hline & $\mathrm{PH}$ & (120) \\
\hline & PTB & $(121)$ \\
\hline \multirow[t]{3}{*}{ PA } & $\mathrm{PH}$ & (122) \\
\hline & PX & (123) \\
\hline & $\mathrm{C} 2$ & $(124)$ \\
\hline \multicolumn{3}{|c|}{ Protein interactions } \\
\hline LBPA & Alix binding & $(125)$ \\
\hline S1P & SCAMPER & (126) \\
\hline $\mathrm{AA}$ & NOX-2 activation & $(127)$ \\
\hline \multicolumn{3}{|c|}{ 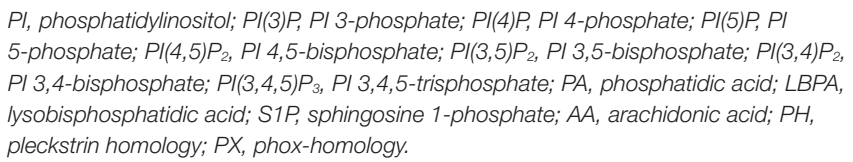 } \\
\hline
\end{tabular}

$\mathrm{PI}(4,5) \mathrm{P}_{2}$ can promote actin polimerization by (i) inducing WASP dependent Arp2/3 activation, (ii) removing capping proteins like profilin from the ends of actin filaments, and (iii) stimulating gelsolin-mediated severing of actin filaments and hence allowing fast growth of barbed ends (91). PI 3-kinase (Vps34) is expressed in early phagosomes (EPs) and causes enrichment in PI 3-phosphate (PI(3)P), which is crucial for EP maturation since it recruits multiple effectors through highly specific interactions with FYVE and phox-homology (PX) domains on target proteins, such as early endosome antigen-1, endosomal sorting complex required for transport (ESCRT)-0, sorting nexins, and p40phox of NADPH oxidase $(100,101)$. In EPs, also PA has an important role because it contributes to the assembly and activation of NADPH oxidase by interacting directly with $\mathrm{p} 47$ phox and by recruiting and activating a number of protein and lipid kinases, including Fgr, the type I PIP5KI, and type 1 sphingosine kinase $(14,102)$. During the transition from early to late phagosome (LP) stage, PI(3)P is then lost as a consequence of hydrolysis catalyzed by a phosphoinositide lipid 3-phosphatases and PI 4-phosphate $[\mathrm{PI}(4) \mathrm{P}]$ is rapidly acquired as a result of the enrichment in $\mathrm{PI}(4) \mathrm{P}$ kinase $2 \mathrm{~A}$ and such acquisition is associated with fusion of autophagosomes 
with lysosomes (LYs) (103). LP stage is also characterized by the presence of PI 5-phosphate [PI(5)P] and PI 3,5-bisphosphate $\left[\mathrm{PI}(3,5) \mathrm{P}_{2}\right]$. In particular, $\mathrm{PI}(3,5) \mathrm{P}_{2}$ can be generated by the enzymatic activity of both $\mathrm{PI} 3 \mathrm{~K}$ and phosphoinositide 5 kinase (PI5K), starting from $\mathrm{PI}(3) \mathrm{P}$ and $\mathrm{PI}(5) \mathrm{P}$, respectively, and takes part in endolysosome morphology, acidification, and trafficking (104). PI(5)P can be directly produced from PI by the means of the PI5K or by dephosphorylation of $\mathrm{PI}(3,5) \mathrm{P}_{2}$ by myotubularin 3 -phosphatases and seems to be involved in actin remodeling and in protein sorting in endosomal compartment (105).

Phospholipids may also contribute to the membrane surface charge. Changes in the content of anionic phospholipids are accompanied by marked alterations in the surface charge of the membrane of nascent phagosome, where proteins that associate with the membrane by electrostatic interactions may relocate (128). For example, the dislocation of phosphoinositides [prevalently $\mathrm{PI}(4,5) \mathrm{P}_{2}$ and $\mathrm{PI}(3,4,5) \mathrm{P}_{3}$ ] causes the modification of surface charge observed after PSL, and the different charge facilitates the dissociation of target proteins causing the termination of signaling and cytoskeleton assembly (92). Similarly, during phagosome maturation, the cytosolic leaflet of phagosomes remains negatively charged and this is prevalently due to accumulation of PS (129). Such a negative charge serves to target proteins with polycationic clusters or polybasic domains and seems to be an important determinant in the distribution of both synaptotagmins, which control membrane fusion events (130), and small GTPases of the Rab and Rho superfamilies, which are critical for both phagosome formation and maturation (131). Thus, the level of anionic phospholipids, including PS and phosphoinositide species, may provide an electrostatic switch to control protein recruitment and vesicle trafficking.

In addition to activation of different signaling pathways, phospholipids can promote phagosome maturation process by inducing positive or negative membrane curvatures. For example, PA is a cone-shaped (type II) lipid that induces negative (concave) curvature of membranes (132), whereas lysobisphosphatidic acid, an inverted cone-shaped fusogenic lipid, forces positive (convex) membrane curvature (125). The resulting changes in membrane curvature activate specific curvature sensors, which are protein motifs or domains, such as amphipathic lipid-packing sensor motifs and BAR domains, which act as geometry sensing tools (133). These sensors play important roles in membrane

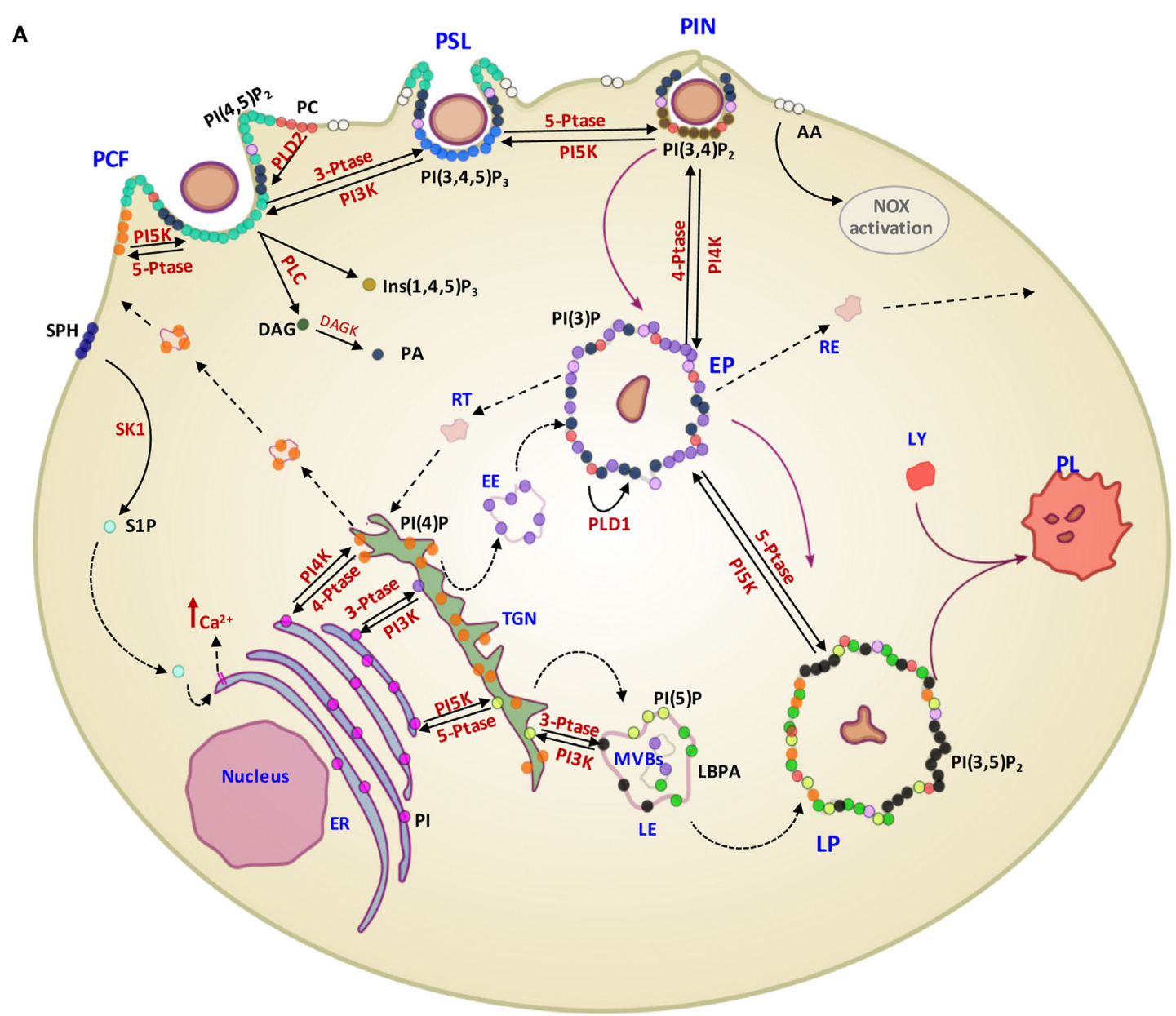

FIGURE 3 | Continued 


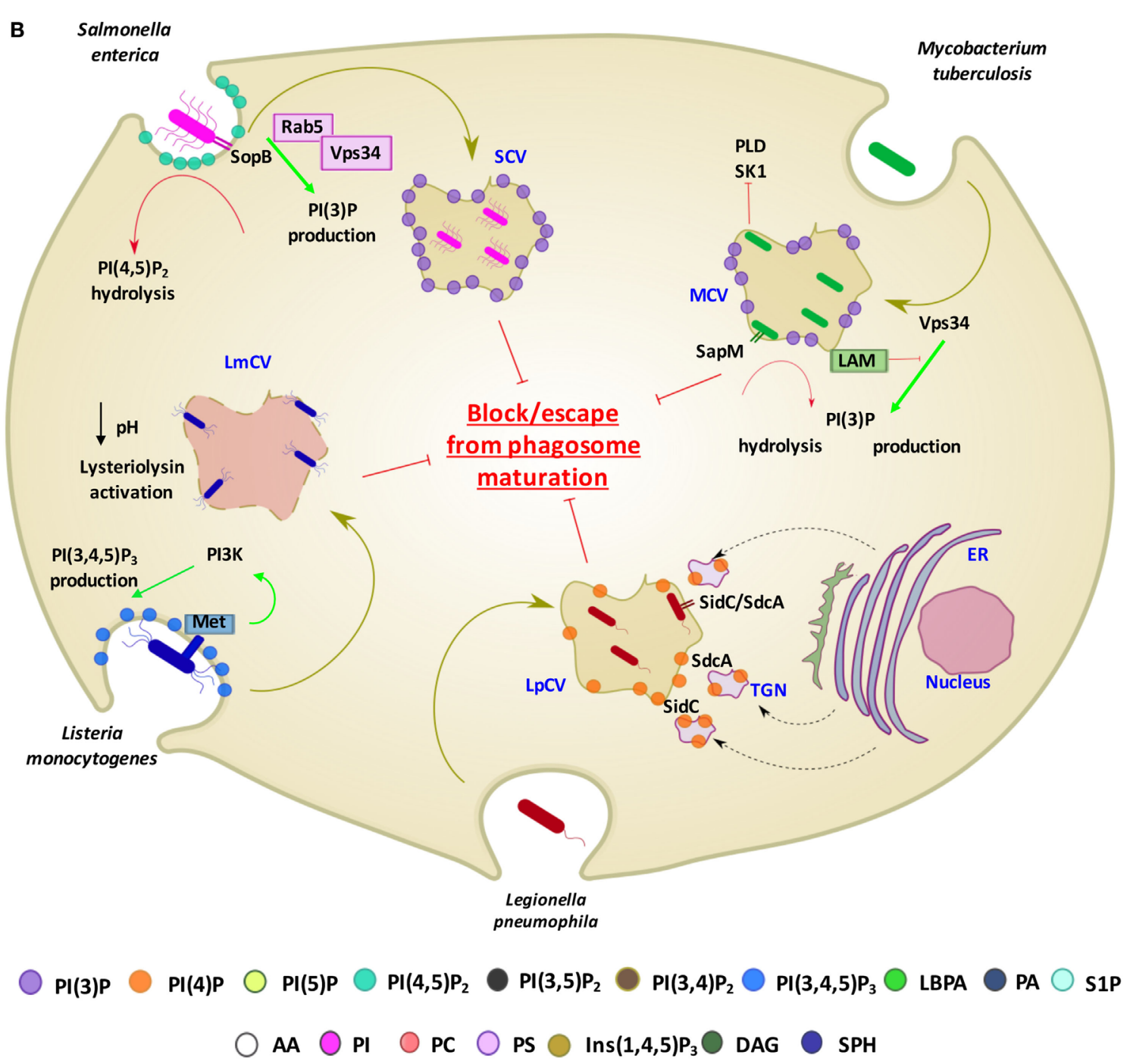

FIGURE 3 | Contribution of different lipid second messengers to phagocytosis from phagosome formation to PL maturation and examples of interference by pathogens. (A) The first event which occur during particulate engulfment is the PCF and the rapid accumulation of PI $(4,5) \mathrm{P}_{2}$ levels, mediated by PI5K and made possible thanks to the translocation of $\mathrm{PI}(4) \mathrm{P}$ from Golgi to the membrane. $\mathrm{PI}(4,5) \mathrm{P}_{2}$ can also be converted in $\mathrm{Ins}(1,4,5) \mathrm{P}_{3}$ and $\mathrm{DAG}$ by the means of $\mathrm{PLC}$ and, furthermore, DAG can be metabolized to PA through the DAGK activity. PA is also early generated by the activation of PLD2, which hydrolyzes PC to PA and choline. Moreover, in this stage, there is a rapid generation of S1P, produced by the phosphorylation of sphingosine by the means of SK1, which in turn may activate sphingolipid $\mathrm{Ca}^{2++}$-release-mediating protein of endoplasmic reticulum (SCaMPER). Following, at the stage of PSL, $\mathrm{PI}(4,5) \mathrm{P}_{2}$ is phosphorylated to $\mathrm{PI}(3,4,5) \mathrm{P}_{3}$ by $\mathrm{PI} 3 \mathrm{~K}$, which is converted to $\mathrm{PI}(3,4) \mathrm{P}_{2}$ by 5-PTase during PIN. EP is characterized by the presence of $\mathrm{PI}(3) \mathrm{P}$, resulting by both its translocation from Golgi and the dephosphorylation of $\mathrm{PI}(3,4) \mathrm{P}_{2}$, mediated by 4-PTase. Although $\mathrm{PA}$ is present in the early stage of phagocytosis process, at this stage its conversion starting to $\mathrm{PC}$ is mediated by the action of PLD1. LP is characterized by the presence of $\mathrm{PI}(3,5) \mathrm{P}_{2}, \mathrm{PI}(5) \mathrm{P}$, and LBPA. In particular, $\mathrm{PI}(3,5) \mathrm{P}_{2}$ can be generated by the enzymatic activity of both $\mathrm{PI} 5 \mathrm{~K}$ and $\mathrm{PI} 3 \mathrm{~K}$, starting from $\mathrm{PI}(3) \mathrm{P}$ and $\mathrm{PI}(5) \mathrm{P}$, respectively. $\mathrm{PI}$ is the precursor of $\mathrm{PI}(3) \mathrm{P}, \mathrm{PI}(4) \mathrm{P}$, and $\mathrm{PI}(5) \mathrm{P}$ and their phosphorylation is mediated by PIK3, PI4K, and PI5K, respectively, in ER. (B) Examples of pathogen interference with host lipid metabolism associated with phagosome maturation. Salmonella enterica secretes the $\mathrm{PI}$ phosphatases SopB, which has a direct effect on the $\mathrm{PI}(4,5) \mathrm{P}_{2}$ hydrolysis and an indirect effect on $\mathrm{PI}(3) \mathrm{P}$ production through the recruitment of Rab5 and its associated enzyme PI3K (Vps34). Mycobacterium tuberculosis (Mtb) produces a secretory acid phosphatase (SapM) and LAM, which hydrolyzes $\mathrm{PI}(3) \mathrm{P}$ and inhibites the generation of PI(3)P, respectively. Moreover, Mtb is able to inhibit SK1 and PLD action. Lysteria monocytogenes invades cells by binding to the host cell Met receptor, which leads to activation of $\mathrm{PI} 3 \mathrm{Ks}$ and $\mathrm{PI}(3,4,5) \mathrm{P}_{3}$ production and promotes a partial phagosome maturation resulting in a pH decrease and lysteriolysin activation. Legionella pneumophila, sequesters endosomes, enriched in PI(4)P, from TGN through SidC and SdcA bacterial proteins, and hence creating replicating vacuoles for itself. Abbreviations for lipids: PI(3)P, PI 3-phosphate; PI(4)P, PI 4-phosphate; PI(5)P, PI 5-phosphate; PI(4,5) $\mathrm{P}_{2}$, PI 4,5-bisphosphate; $\mathrm{PI}(3,4) \mathrm{P}_{2}$, PI 3,4-bisphosphate; PI(3,4,5) $\mathrm{P}_{3}$, PI 3,4,5-trisphosphate; LBPA, lysobisphosphatidic acid; PA, phosphatidic acid; AA, arachidonic acid; PI, phosphatidylinositol; PC, phosphatidylcholine; PS, phosphatidylserine; Ins $(1,4,5) \mathrm{P}_{3}$, inositol 3,4,5 trisphosphate; DAG, diacylglycerol; SPH, sphingosine; S1P, sphingosine 1-phosphate; LAM, lipoarabinomannan. Abbreviations for enzymes: PLD-1, phospholipase D-1; PLD-2, phospholipase D-2; PLC, phospholipase C; DAGK, diacylglycerol kinase; SK1, sphingosine kinase 1; PI3K, phosphoinositide 3-kinase; PI4K, PI 4-kinase; PI5K, phosphoinositide 5 kinase; 3-PTase, PI 3-phosphatase; 4-PTase, PI 4-phosphatase; 5-PTase, PI 5-phosphatase; Other abbreviations: PCF, phagocytic cup formation; PSL, phagosome sealing; PIN, phagosome internalization; EP, early phagosome; LP, late phagosome; PL, phagolysosome; LY, lysosome; EE, early endosome; LE, late endosome; MVBs, multivesicular bodies; RE, recycling endosome; RT, retrograde traffic; TGN, trans Golgi network; ER, endoplasmic reticulum; SCV, Salmonella containing vacuole; MCV, Mycobacterium containing vacuole; LmCV, Listeria containing vacuole; LpCV, Legionella containing vacuole. 
trafficking and remodeling, by regulating membrane protein concentration, enzyme activation, lipid composition, and vesicle fusion events (134).

The translocation of PS on the outer leaflet of plasma membrane represents one of the early events of apoptosis, occurring in both infected and uninfected apoptotic cells, and represents an "eat-me" signal for macrophages (135-138). The functional consequence of a PS-dependent recognition and phagocytosis of apoptotic bodies (efferocytosis) by macrophages is the release of TGF- $\beta$, IL-10, and the inhibition of the production of proinflammatory cytokines, such as TNF- $\alpha$ and IL-1 $\beta$ (139). These features have been previously reported as a possible therapeutic strategy to reduce immunopathologic responses $(136,140)$. However, if phagocytosis involves apoptotic bodies derived from cells expressing PAMPs, as in the case of apoptosis mediated by an infectious agent, phagocytosis causes activation of antigen-presenting cells (APCs) and release of IL-6, TGF- $\beta$, and IL-23, leading to a preferential activation of pro-inflammatory Th17 cells (141). Moreover, apoptotic bodies from macrophages infected by Mycobacterium bovis bacille Calmette-Guerin (BCG) have been reported to promote antigen cross-presentation and $\mathrm{CD}^{+} \mathrm{T}$ cell activation as well as an in vivo increased protection against experimental TB in mice (142). Coherently, emulsified PS has been described as a simple and efficient carrier to deliver antigenic peptide epitopes to professional APCs to induce both helper and cytotoxic T cell response in vivo (143).

Considering the crucial role of lipids in the activation of antimicrobial response, many intracellular bacterial pathogens evolved strategies aimed at interfering, at different levels, with lipid metabolism to generate specific pathogen-containingvacuoles permitting their intracellular survival (14) (Figure 3B). Salmonella enterica exploits type III secretion system to secrete the PI phosphatases SopB, a phosphoinositide phosphatases able to dephosphorylate $\mathrm{PI}(4,5) \mathrm{P}_{2}$. Decreased levels of $\mathrm{PI}(4,5) \mathrm{P}_{2}$ reduce the surface charge of the Salmonella containing vacuole (SCV) and promote membrane fission by reorganizing the actin cytoskeleton during bacterial internalization (144). SopB also recruits the RAB GTPase RAB5 protein and the RAB5 effector Vps34, a PI3K that accumulates PI(3)P on the SCV surface and interferes with the maturation to next LP stage (144). Listeria monocytogenes invades host cells by recognition of Met receptor by bacterial internalin $\mathrm{B}$ (InlB), which leads to the PI3K activation and consequent enhancement of $\mathrm{PI}(3,4,5) \mathrm{P}_{3}$ levels. Such increase in $\mathrm{PI}(3,4,5) \mathrm{P}_{3}$ promotes the fusion of early endosomes with the bacterial vacuole, allowing partial maturation of phagosome before lysis of the phagosome and escape into cytoplasm due to the $\mathrm{pH}$-dependent activation of listeriolysin (145). Legionella pneumophila, through SidC and SdcA proteins, anchors to PI(4)P expressing endosomes from trans Golgi network to form a replicative niche for the pathogen (146). Mtb, as well as BCG, interferes with PL maturation $(15,136,147)$ by depleting the phagosome of PI(3)P and hence arresting the vacuole in an immature form (148). The mycobacterial secretory acid phosphatase (SapM) acts in concert with the mycobacterial lipoarabinomannan (LAM), a phosphatydilinositol analog, to avoid the formation of PI(3)P by hydrolysis of the phosphate group (149) and by inhibiting the activity of type III PI3K Vps34 (150), respectively. Finally, an inhibition in host
PLD activation was observed during early phases of interaction between Mtb and macrophage (151). This inhibition was not due to differences in protein expression, suggesting a metabolic control of the enzyme. Interestingly, an upstream inhibition of sphingosine-kinase exerted by Mtb was also reported which may be responsible of the reduced calcium mobilization (152) and the consequent inhibition of $\mathrm{Ca}^{++}$-dependent PLD activation (153) observed during in vitro Mtb infection.

Given the well-defined role of certain lipids in the physiology of phagocytosis, the possibility to modulate the phagosome maturation process by the use of bioactive lipids has been suggested as a strategy to increase the efficacy of innate bactericidal mechanisms. In this context, Anes et al. showed that selected bioactive lipids, such as arachidonic acid, ceramide, sphingosine, sphingomyelin, and sphingosine 1-phosphate (S1P), activate phagosome actin assembly and maturation resulting in killing of pathogenic mycobacteria in murine macrophages (154). Moreover, S1P and its analog lysophosphatidic acid (LPA) were both described to activate PLD-mediated and PL maturationdependent mycobactericidal response in human macrophages $(155,156)$ and in type II alveolar epithelial cells (157) in in vitro models of $\mathrm{Mtb}$ infection, highlighting the role of PA in the activation of antimycobacterial response. Interestingly, and of high translational value, both lysophospholipids promoted antimicrobial response, resulting in a significant intracellular killing of endogenous mycobacteria, in bronchoalveolar lavage (BAL) cells from pulmonary TB patients $(155,158)$. Finally, the intranasal administration of S1P or LPA in murine models of primary Mtb infection significantly reduced pulmonary mycobacterial burden and histophatology $(156,159,160)$. On these grounds, the targeted delivery of several bioactive lipids into macrophages to increase their innate anti-bacterial mechanisms could be useful for the treatment of Mtb infection. However, such a delivery is challenging, due to lipid pharmacokinetic properties and to the difficulties to target specific cells. The possibility to incorporate lipid second messengers in Janusfaced liposomes may represent a strategy to overcome these limitations $(15,136)$. The main feature of these liposomes is the asymmetric distribution of phospholipids within the liposome membrane, with inner leaflet expressing bioactive lipids involved in phagosome maturation, and the outer surface expressing PS, representing an "eat-me" signal for macrophages. PA delivered by this strategy allowed to enhance PL maturationdependent (myco)bactericidal response of macrophages and BAL cells from TB patients as well as from patients affected by MDR bacterial pneumonia $(15,136)$. Notably, both PA and PI(5)P delivered by Janus-faced liposomes were able to enhance antimicrobial response against Pseudomonas aeruginosa in an in vitro cellular model of cystic fibrosis by using macrophages expressing a pharmacologically inhibited or a naturally mutated cystic fibrosis transmembrane conductance regulator (15), which are characterized by impaired phagosome maturation (161). These experimental evidences suggest the possibility to use liposomes to deliver bioactive lipids to enhance phagosome maturation-dependent antimicrobial response and to restore the PL maturation pathway, which can be corrupted by specific pathogens (15). 


\section{LIPOSOMES AS “INDIRECT” ENHANCERS OF ADAPTIVE ANTIMICROBIAL RESPONSE}

Vaccines represent a great contribution of medical sciences to the reduction of the deaths caused by infectious diseases. The majority of currently available vaccines induce neutralizing or opsonizing pathogen-specific antibody responses to protect against infectious diseases. However, a number of diseases are caused by pathogens that are not controlled by humoral responses and novel vaccine formulations aimed at generating protective pathogen-specific immune responses are under testing or development. According to the pathogen virulence factors or mechanisms of pathogenesis, novel vaccines are being designed to enhance either cellular immune responses, with prevalence of cytotoxic T cells, or polarization of specific $\mathrm{T}$ cell subpopulations, or aimed at increasing the response at mucosal or systemic sites. One of the strategies currently under development is based on the use of recombinant antigens (subunit vaccines) in association with adjuvants able to modulate/polarize the developing immune response. Recombinant antigens show a higher safety profile and lower reactogenicity, but are characterized by a reduced immunogenicity in comparison with inactivated or attenuated whole cell vaccines. As a consequence, adjuvants are generally included to vaccine formulations to provide the necessary inflammatory microenvronment required for the activation of innate immunity cells and the following priming and expansion of naïve $\mathrm{T}$ cells for the development of appropriate adaptive immune response. Thus, adjuvants are generally defined as substances that (i) facilitate a depot effect and deliver the antigen in proximity of APC, (ii) generate an inflammatory microenvironment necessary for the activation of APC, and (iii) induce the secretion of specific cytokine patterns by APC for the differentiation of naïve T cells into different $\mathrm{CD}^{+}$and/or $\mathrm{CD} 8^{+} \mathrm{T}$ cell subpopulations.

In addition to their suitability as drug carriers, liposomes represent an extraordinary tool for the devise of innovative vaccines, as they can be designed for the antigen delivery (see chapter 5) and/or for their possible adjuvancy function (162). In fact, several liposome adjuvants have been licensed for human use and others are being evaluated in clinical trials (Table 4). However, many other formulations are possible and have been or could be tested for efficacy and safety. In this regard, different liposome adjuvant formulations can be produced with different properties according to the (i) lipid composition, (ii) liposome size, (iii) liposome charge, and (iv) inclusion of function modifiers such as PAMPs.

\section{Lipid Composition}

The choice of liposomal lipid composition (in terms of hydrocarbon length, unsaturation, charge, and headgroup species of the lipids) influences the physico-chemical features of the liposomes, such as the lipid bilayer fluidity, which can in turn influence immune response. For instance, the degree of saturation or the length of fatty acids may affect the strength of the van der Waals forces among neighboring chains. Thus, phospholipids with longer saturated hydrocarbon chains show higher tendencies to interact each other and to form rigidly ordered bilayer structures than shorter and/or unsaturated hydrocarbon chains, which form liposomes with fluid and disordered bilayers (163). Membrane liposome fluidity in turn affects antigen presentation as it has been previously shown that fluid disordered phase liposomes promoted MHC class I presentation pathway to a higher degree than the solid ordered liposomes (164). Furthermore, in in vivo studies, solid ordered liposomes prepared using dimethyldioleoylammonium (DDA) induced 100-fold higher Th1 response than the fluid liposome counterpart prepared using the unsaturated analog DDA bromide (165). Inclusion of Chol is also known to influence bilayer fluidity and is commonly incorporated within liposomes as it can enhance liposome stability. The impact of Chol on adjuvancy is actually controversial, with some studies showing improvements and others reduction of immune response (166). Cationic adjuvant formulation (CAF)01 is actually a commercially available liposome adjuvant formulation that is composed of DDA stabilized with trehalose 6,6-dibehenate (TDB), a glycolipid synthetic variant of mycobacterial cord factor. TDB activates macrophages and dendritic cells (DCs) via SykCard9-Bcl10-Malt1 signaling pathway and when administrated

TABLE 4 | Examples of liposome adjuvants vaccines against infectious disease in market or tested in clinical trials.

\begin{tabular}{|c|c|c|c|c|c|}
\hline Target & Immuno modulators & Lipid formulation & Antigen & Phase & $\begin{array}{c}\text { Clinical trials.gov } \\
\text { identifier }\end{array}$ \\
\hline HAV & $\mathrm{HA}+\mathrm{NA}$ & DOPC:DOPE & Inactivated HAV & Licensed (Epaxal $\left.{ }^{\circledR}\right)$ & \\
\hline Human papilloma virus & $\begin{array}{l}\text { MPLA + aluminum hydroxide } \\
\text { (ASO4) }\end{array}$ & n.d. & L1 & Licensed (Cervarix $\left.{ }^{\circledR}\right)$ & \\
\hline Influenza virus & - & DOPC:DOPE & $\mathrm{HA}$ & Licensed (Inflexal $\left.{ }^{\circledR}\right)$ & \\
\hline Influenza virus & - & CCS/C ("VaxiSome") & $\mathrm{HA}$ & $\|$ & NCT00915187 \\
\hline Mycobacterium tuberculosis & TDB (CAF01) & DDA & Ag85b + ESAT6 & 1 & NCT00922363 \\
\hline Plasmodium Falciparum & MPLA + QS21 (AS01) & n.d. & RTS,S & III & NCT00872963 \\
\hline P. falciparum & MPLA + QS21 (AS01) & n.d. & FMP012 & 1 & NCT02174978 \\
\hline P. falciparum & MPLA + QS21 (AS01) & n.d. & $\mathrm{RH} 5.1$ & l/lla & NCT02927145 \\
\hline P. falciparum & EPA/AS01 & n.d. & Pfs25M + Pfs230D1 & 1 & NCT02942277 \\
\hline
\end{tabular}

This compilation was generated with data from ClinicalTrials.gov.

DOPC, dioleoyIPC; DOPE, dioleoly-sn-glycero-phophoethanolamine; DDA, dimethyldioleoylammonium; HA, hemaglutinin; NA, neuroaminidase; TDB, trehalose6, 6-dibehenate; MPLA, monophosphoryl lipid A; QS21, triterpene glucoside compound derived from the Quillaja saponaria tree; CCS, N-palmityol-derythro-sphingosyl-Carbamoyl-Spermine; CCS/C, N-palmityol-derythro-sphingosyl-Carbamoyl-Spermine/Cholesterol; EPA, ExoProtein A (a detoxified form of exotoxin A from Pseudomonas aeruginosa); n.d., not determined; CFA, cationic adjuvant formulation; HAV, hepatitis A virus. 
in combination with a Mtb subunit vaccine induced a robust and combined antigen-specific Th1 and Th17 responses and partial protection against Mtb challenge $(165,167)$.

\section{Liposome Size}

The dimension of liposomes can impact adjuvant efficacy and several studies have shown that Th1 or Th2 response can be evoked by using particles with different diameter (168). In this context, a significantly higher Th1 response, as measured in terms of IL-12-dependent IFN- $\gamma$ secretion and serum IgG2a production, has been reported following vaccination with large vesicles ( $\geq 225 \mathrm{~nm}$ diameter), whereas the same antigen encapsulated in small liposomes ( $\leq 155 \mathrm{~nm}$ diameter) induced a prevalent Th2 response as determined in terms of IgG1 and increased lymph node (LN) IL-5 production (169). Such a different outcome can reflect differences in particle trafficking to LNs: small particles $(20-200 \mathrm{~nm})$ freely traffics to the draining LNs where they are taken up by LN resident DCs, whereas larger vesicles $(500-2,000 \mathrm{~nm})$ are internalized by tissue-resident DC (170). Different antigen presentation pathway has also been observed following internalization by phagocytes: antigen encapsulated in large $(560 \mathrm{~nm})$ vesicles localized in early immature phagosomes, where class II antigen-processing pathway could be intercepted for recognition by $\mathrm{CD} 4^{+} \mathrm{T}$ cells, while antigen encapsulated in small $(155 \mathrm{~nm})$ vesicles were rapidly transferred to late endosomes/lysosomes, with a consequent reduced class II-restricted Ag-presenting efficiency (171).

\section{Liposome Charge}

Liposome charge may have critical effects on the adjuvant properties of liposomes. Cationic liposomes may interact with the negatively charged mucosal surfaces and exibit increased mucoadesion, leading to reduced clearance rate, prolonged exposure time of the antigen at the mucosal surface (depot effect), enhanced endocytosis of liposomes by APC (13, 172-175), and increased cell-mediated immune response (173) when compared with neutral liposomes, which tended to induce antibody immune response (176). However, anionic liposomes may also modulate immune response in the context of novel formulations of liposomal adjuvants. As above described, PS is expressed on the outer membrane leaflet of apoptotic bodies and represents an "eat-me" signal for macrophages and DC, which express specific PS receptors. Phagocytes that internalize apoptotic bodies through PS became polarized toward a tolerogenic response (177). However, when the recognition occurs in the presence of selected PAMPs a Th17-differentiating cytokine profile is produced (170) and a similarly efficient class II- and class I-restricted antigen presentation is induced (143).

\section{Function Modifiers}

The procedures of liposome preparations make possible to include within the liposome structure different function modifiers molecules, such as PAMPs. The addition of function modifiers molecules may permit to design APC-targeted liposomes able to modulate the effector function of APC, including the profile of secreted cytokine that, in turn, can induce the differentiation of diverse T helper cell subpopulations (178). For example, the immunization of mice with liposomes containing ovalbumin (OVA) and oligodeoxynucleotide (ODN) with CpG motifs (ligand for TLR-9) induced a Th1-type immune response, with enhanced production of IFN- $\gamma$ and of IgG2a, whereas the same antigen encapsulated with Pam3CSK4 (a TLR-2 ligand consisting of tri-palmitoyl-S-glyceryl cysteine lipopeptide with a pentapeptide SKKKK) induced increased levels of IgG1, suggesting a Th2-oriented immune response $(179,180)$. Another example is given by the lipophilic muramyldipeptide (MDP) analogs MDP phosphatidylethanolamine as well as the MDP glyceroldipalmitate that induced higher antibody titers, Th1 response, and IFN- $\gamma$ levels if added to liposomal formulations containing hepatitis B surface antigen (HBsAg) (181). Thus, the use of different PAMPs can modulate the immune response against the same antigen, in dependence on the targeted TLR.

Monophosphoryl lipid A (MPLA) is a safe and potent liposome adjuvant used with many candidate antigens for new vaccines in the fight against several types of cancer and anti-infective vaccines such as malaria and HIV-1 (182). For example, RTS,S (a particulate antigen consisting of hepatitis B particles coexpressing epitopes derived from $P$. falciparum circumsporozoite protein) induced an in vivo cytotoxic T-lymphocyte response and a dose-dependent enhancement of the specific IgG levels when entrapped in liposomes containing MPLA and not when encapsulated in liposomes missing MPLA (183). Moreover, a recent paper demonstrated that the $P$. falciparum Protein-013 can induce a potent and sterilizing immune response when formulated with small ULV containing a synthetic MPLA derivative $\left(3 \mathrm{D}-\mathrm{PHAD}^{\circledR}\right)$ and the QS-21 (184). Similarly, Nagill and Kaur encapsulated the $78-\mathrm{kDa}$ antigen of Leishmania donovani with MPLA, resulting in decreased parasite burden after challenge in immunized mice (185).

Korsholm et al. described a novel $\mathrm{CD}^{+}$T-cell-inducing adjuvant, CAF09, consisting of DDA-liposomes stabilized with monomycoloyl glycerol-1 (a synthetic analog of a mycobacterial cell wall lipid and a potent stimulator of human DCs) and combined with the TLR3 ligand Poly(I:C) (186). CAF09 was used to test immunogenicity of the model antigen OVA as well as several antigens of Mtb (TB10.3, H56), HIV (Gag p24), HPV (E7) in mice and resulted in a high frequency of antigen-specific $\mathrm{CD}^{+} \mathrm{T}$ cells (186). In the mouse model of subcutaneous HPV-16 E7-expressing TC-1 skin tumor, immunization with the E7 antigen and CAF09 as adjuvant significantly reduced the growth of the tumor (186). Another widely studied liposome carrier is the cationic liposome-DNA complex (CLDC) that is prepared by mixing liposomes and ODN with CpG motifs, which activate TLR9. Bernstein and colleagues demonstrated that CLDC increased the immune response against simian immunodeficiency virus induced by vaccines. The immunization of rhesus macaques with CLDC induced a potent virus-specific $\mathrm{B}$ - and T-cell response in comparison to control animals $(12,187)$. Moreover, in mice expressing hepatitis B virus, the CLDC was tested as adjuvant for HBsAg. Whereas HBsAg induces only a B-cell immune response, the viral antigen formulated together with CLDC elicited both T- and B-cell responses $(12,188)$. 


\section{LIPOSOMES AS ANTIGEN CARRIER IN INNOVATIVE VACCINE PREPARATIONS}

Allison and Gregoriadis were the first to describe the capacity of liposomes to elicit immune responses against associated or incorporated antigens $(12,189)$. Water-soluble compounds (peptides, proteins, carbohydrates, nucleic acids, and haptens), depending on the chemical properties, can be linked to the surface of liposomes, by stable chemical bond or by adsorption, or can be trapped inside the aqueous inner space, whereas lipophilic compounds (antigens, lipopeptides, linker molecules, and adjuvants) can be inserted into the lipid bilayer $(12,190)$. Surface-exposed antigens are available for and can stimulate B-cell for antibody production, while both surface-exposed and encapsulated antigens, which require intracellular liposome disruption to be accessible, may induce T-cell responses. Liposome-encapsulated protein antigens have been frequently used and several studies well documented the MHC class-I presentation and induction of cytotoxic T lymphocytes (CTLs) by antigens formulated inside liposomes. $\mathrm{H}-2$ antigens entrapped in egg lecithin plus Chol (30\% w/w) liposomes induced a potent anti-H-2 CTL allo-response (191). Human LS174T colon tumor cell membranes encapsulated into liposomes (PC/Chol/PA 7:2:1) elicit in vitro specific primary and secondary xenogeneic immune responses in murine splenocytes (192). Induction of antiviral immunity by liposome-encapsulated peptides was tested by Ludewig and colleagues that showed the high immunogenicity of peptides derived from the glycoprotein of the lymphocytic choriomeningitis virus when administered intradermally in mice (193). In addition, these authors used the liposome to prime a strong MHC class I-restricted T-cell response specific for 10 diverse epitopes of hepatitis $\mathrm{C}$ virus (HCV) $(12,194)$. In the fight against Ebola Zaire (EBO-Z) virus, the protective efficacy of liposome-encapsulated [L(EV)] irradiated $\mathrm{EBO}-\mathrm{Z}$, containing all of the native $\mathrm{EBO}-\mathrm{Z}$ proteins was evaluated (195). Mice immunized intravenously with L(EV) and challenged with a uniformly lethal mouse-adapted variant of EBO-Z were totally protected from illness and death compared with mice vaccinated intravenously with the irradiated virus nonencapsulated that presented a $55 \%$ of survival (195). Liposomes were also formulated with the $\mathrm{pH}$-sensitive 3-methyl-glutarylated hyperbranched poly(glycidol) (MGlu-HPG) and used to entrap OVA. Such MGlu-HPG formulations elicited a strong $\mathrm{T}$ cell activation that was inhibited using blocking antibodies against MHC class-I/MHC class-II molecules, suggesting the involvement of MHC class I- and II-restricted antigen presentation (12, 196). Ding and colleagues developed the so-called RAFTsomes, a liposome incorporating membrane microdomains of APCs with enriched epitope/MHC complexes. OVA epitope loaded RAFTsome immunization gave high anti-OVA IgG1 levels and the immunized mice were protected from OVA-expressing EG.7 tumor cell inoculation challenge (197).

Mucosal surfaces are the main entry site for most environmental antigens and the mucosal immunity plays a critical role in preventing the initial infection of many pathogens. Several studies are focused on figuring out the ability of liposomes to act as efficient mucosal antigen delivery system. A potential mucosal carrier formulation has been developed by Gupta and Vyas that encapsulated HBsAg in liposomes coupled with Ulex europaeus agglutinin 1, a lectin isolated from $U$. europaeus seeds. After oral immunization, lectinized liposomes were predominantly targeted to $\mathrm{M}$ cells on intestinal Peyer's patches, inducing a strong anti-HBsAg IgG response in serum, anti-HBsAg IgA in various mucosal fluids, and cytokine levels in the spleen homogenates (198). Figueiredo and colleagues described another mucosal formulation composed of Streptococcus equi antigens encapsulated inside PC/Chol/SA liposomes or inside chitosan nanoparticles. Mice immunized intranasally with both delivery systems developed mucosal, humoral, and cellular immune responses, but higher secretory IgA levels in the lung were observed following vaccination with chitosan nanoparticles, due to their enhanced mucoadhesive properties $(12,199)$. Wang and colleagues encapsulated the OVA in a galactosylated liposome carrier in which a galactosyl lipid (galactose conjugated covalently with 1,2-didodecanoyl-sn-glycero-3-phosphoethanolamine) was incorporated into a liposomal bilayer. OVA-encapsulated targeted galactosylated liposome elicited in the nasal and lung wash fluid a significantly higher OVA-specific secretory IgA titers and serum IgG antibody levels than control mice (200). Traditional phosphodiester liposomes are not stable and could be easily degraded in the gastrointestinal tract. Zhang and colleagues described the archaeosomes, a novel oral delivery system based on the polar lipid fraction E isolated from Sulfolobus acidocaldarius. The archaeosomes had significant higher stability in simulated gastric and intestinal fluids after oral administration and induced a strong serum IgG as well as mucosal IgA immune response. Moreover, such delivery system elicited antigen-specific MHC class I-restricted T cell proliferation (201).

Liposomes are versatile tool to encapsulate and deliver a wide range of molecules, not only proteins but also glycolipid antigens. Kallert et al. demonstrated that purified mycobacterial LAM can be efficiently delivered into $\mathrm{CD} 1^{+} \mathrm{APC}$ via liposomes and this delivery system induces robust LAM-specific Th1-biased CD1restricted T-cell responses in primary human cells (202). The authors used liposomes consisted of egg-PC, $\mathrm{Chol}$, and stearylated octaarginine and proved that octaarginine, a cell-penetrating peptide consisting of eight positively charged arginines, increases the glycolipid antigen accumulation into lipid-APCs. The efficacy of octaarginine-containing liposomes was also tested in in vivo models of immunization using both BCG primed guinea pigs (203), where these liposomes induced a delayed type hypersensitivity reaction in the skin and in rhesus macaques, using glucose monomycolate (GMM) as antigen, where a CD1-restricted Th1-skewed immune response was observed $(202,204)$. In a recent study, GMM-containing liposomes were decorated with a high-affinity glycan ligand of the sialic acid-binding Ig-like lectin-7, a siglec receptor expressed on DC that mediates rapid endocytosis and transport of its cargo to LYs (205). This elegant targeting platform leads to a robust GMM-specific CD1-restricted activation of $\mathrm{T}$ cells. One way to ensure rapid and specific liposome uptake by leukocyte subsets is decoration of liposomes with antibodies against a cell subset-specific antigen. Klauber et al. reported a liposomal drug delivery system for robust and specific targeting of monocytes and DCs consisting of sterically stabilized liposomes with surface-conjugated antibodies against 
C-type lectin "Dendritic Cell Immunoreceptor" (206). Using this method, they were able to activate the targeted cells and improve the ability of the agonist to induce secretion of key anticancer cytokines (IL-12p70, IFN- $\gamma$, and IFN- $\alpha$ ).

Typically, exogenous antigens residing in proteolytic PLs are directed to MHC class II-expressing compartments (MIIC) where peptides resulting from antigen proteolysis are loaded on the neoformed class II molecules to be expressed on cell membrane. Thus, bioactive lipids like PI(3)P, promoting (auto) PL biogenesis, can in turn promote class II antigen presentation pathway (207). Harding and colleagues (208) used liposomes composed of dioleoyl PC/dioleoyl PS (DOPC/DOPS) or dioleoyl phosphatidylethanolamine/palmitoyl homocysteine (DOPE/ $\mathrm{PHC}$ ) at 4:1 molar ratios with four different encapsulated protein antigens (OVA, murine hemoglobin, bovine ribonuclease, or hen egg lysozyme) and proved that macrophages efficiently processed the encapsulated Ag. These liposomes were able to sequester their contents from potential endosomal processing events and release them only after delivery to LYs for efficient MHC class II presentation (208).

The antigen presentation pathway leading to the loading of exogenous antigens on MHC class I molecules is called crosspresentation. Cross-presentation can occur via a vacuolar and a cytosolic pathway. The vacuolar pathway bypasses the cytosolic steps and TAP- or proteasome-sensitivity, is dependent on lysosomal proteases, and invokes a peptide exchange step for reloading of endocytosed MHC-I complexes, which are then rerouted directly back to the plasma membrane in a Brefeldin A-insensitive manner (209). The cytosolic route, considered to be the most important, is TAP and proteasome dependent and allows the export of the antigen into the cytosol through the acquisition of the traslocon SEC61 on antigen-containing endosomes from the endoplasmic reticulum (ER)-associated degradation pathway (210). Although no specific lipid second messengers promoting cross-presentation pathway have been identified so far, the involvement of specific membrane contact sites between ER and phagosomes (211) suggests that specific signal lipids can be involved. The permanence of the antigen in a non-proteolytic compartment represents a condition promoting cross-presentation and explains why DC, whose phagosomes show reduced acidity and limited proteolysis, have better cross-presentation capability than macrophages. In this context, cationic liposomes, but not anionic liposomes, that increase the lysosomal $\mathrm{pH}$ in $\mathrm{DCs}$ and reduce antigen degradation, promote antigen cross-presentation and $\mathrm{CD}^{+} \mathrm{T}$-cell cross-priming $(212$, 213). As an alternative strategy to promote antigen delivery to cytoplasm and make it available for class I antigen presentation, Miura et al. developed liposomes carrying OVA modified with KALA peptide, an $\alpha$-elical cationic peptide derived from the sequence of the $\mathrm{N}$-terminal segment of the hemagglutinin (HA)-2 subunit of the influenza virus $\mathrm{HA}$, which is involved in the fusion of the viral envelope with the cell membrane (214), and show membrane destabilizing properties (215). MHC class I presentation pathway can also be favored using $\mathrm{pH}$-sensitive liposomes. For example, Reddy et al. have shown that OVA entrapped in $\mathrm{pH}$-sensitive liposomes (DOPE/1,2-dioleoyl-snglycero-3-succinate 1:1 and DOPC/PS/Chol 5:2:3) allowed MHC class I presentation of OVA peptides by mouse thymoma cells, which were lysed by OVA-specific CD8 ${ }^{+}$T lymphocytes (216).

Liposomes can be designed to carry antigens within the acqueous phase, encapsulated inside the lipid bilayer, or exposed onto the liposome surface and this can result in different outcomes of the immune response. Investigation of HA adsorption versus encapsulation and coencapsulation of ODN with $\mathrm{CpG}$ motifs in $3 \beta-\left[N-\left(N^{\prime}, N^{\prime}\right.\right.$-dimethylaminoethane $)$-carbamoyl $]$ Chol (DC-chol) liposomes demonstrated that encapsulated HA was less immunogenic than adsorbed HA (217). Moreover, Takagi and colleagues immunized human-HLA-transgenic mice with liposomes exposing several epitope-peptides derived from $\mathrm{HCV}$ in their external layer and observed that 1 mouse- and 3 human MHC-restricted peptides protected and conferred longterm memory to vaccinated animals (218). Immunization of HLA-A ${ }^{\star} 0201$-transgenic mice with liposomes conjugated with peptides designed according to the sequence of highly conserved antigens of influenza viruses and HLA-A 0201 binder, induced antigen-specific $\mathrm{CD}^{+} \mathrm{T}$-cells, and mediated protection of mice challenged intranasally with the influenza viruses $\mathrm{H} 1 \mathrm{~N} 1$ or $\mathrm{H} 3 \mathrm{~N} 2$ (219). Similarly, when the peptide nucleoprotein (NP)366-374, designed according to the sequence of the NP of influenza $\mathrm{H} 3 \mathrm{~N} 2$ virus, was coupled with liposomes and used to immunize mice induced peptide-specific $\mathrm{CD}^{+} \mathrm{T}$-cells and the replication of influenza H3N2 virus was successfully suppressed in the lung of challenged mice (220). Naito and colleagues reported that OVA chemically coupled with the surface of liposome via amino groups using glutaraldehyde induced Ag-specific IgG but not IgE Ab production (221), showing that liposomes can be exploited to develop vaccines devoid of allergenic potential. Moreover, liposomes showed different capacities to induce class I or class II presentation of the delivered antigen depending on the mobility of their membranes. Taneichi et al. reported that OVA coupled with liposome constituted by unsaturated fatty acid was presented to both $\mathrm{CD}^{+}$and $\mathrm{CD}^{+} \mathrm{T}$ lymphocytes, while OVA conjugated to liposomes constituted by saturated fatty acid were not presented to $\mathrm{CD} 8^{+} \mathrm{T}$ lymphocytes (222). The in vivo induction of CTL and the eradication of E.G7 tumor in mice confirmed the capacity to induce cross-presentation by Ag-conjugated liposomes prepared including unsaturated fatty acid in the bilayer (222). Masek and colleagues used small $\mathrm{Ni}$-chelating liposomes exposing on their surface the Candida albicans His-tagged antigen hsp (hsp90-CA) with the MDP derivative $\mathrm{C} 18-0-6$-norAbuMDP as adjuvant. These liposomes were phagocytosed by human DCs in vitro and in vivo in mice, where induced antigen-specific Th1 and Th2 responses without side effects (223). At least in theory, the covalent attachment of protein antigens to nanocarriers could modify protein structure and mask epitopes, altering the antibody response. Watson and colleagues tested this hypothesis using metal chelation via nitrilotriacetic acid (NTA) to attach antigens to liposomes instead of covalent linkage. OVA and a peptide derived from the membrane-proximal region of HIV-1 gp41 (N-MPR) were attached via NTA or covalent linkage. Covalently attached N-MPR or OVA elicited stronger antibody responses than NTA-anchored antigens excluding the possible masking effect of covalent binding (224). Finally, antigen modification may 
also impact the response against haptens as reported by a study by Matyas et al., where the authors conjugated haptenic compounds to protein carriers and embed them in the outer surface of MPLA-containing liposomes. Four synthetic opiate haptens were conjugated to carrier proteins and induced high levels of specific antibodies to synthetic heroin haptens following in vivo immunization that might be useful as a candidate vaccine to heroin and similar opiates (225).

Self-amplifying messenger RNA (mRNA) technology has been developed for in situ expression of antigens and represents a new platform for innovative vaccine applications (226) with the advantage that unlike DNA, mRNA-based vaccines do not integrate into chromosomes avoiding the risks of oncogenesis and insertional mutagenesis (227). Liposomes were identified as the more suitable delivery system for non-amplifying or selfamplifying mRNA vaccine, and it was rapidly evident that mRNA encapsulated inside liposomes can activate innate immunity through toll-like and RIG-I-like receptors $(228,229)$.

Richner and colleagues tested the efficacy of this novel technology in a vaccine against Zika virus using a modified mRNAencoding prM-E gene that produced virus-like particles with a reduced cross-reactivity with the related dengue virus (230). Two immunizations induced a strong protective humoral response against Zika infection in mouse model and reduced the crossreactive response against the related virus dengue. For this experiment, liposomes were obtained taking advantage of a method developed by Chen and colleague, consisting of ionizable lipid, DSPC, CHOL, and PEG-lipid (dissolved in ethanol at the molar ratios 50:10:38.5:1.5) combined with a citrate buffer containing mRNA (3:1 = aqueous:ethanol, $\mathrm{pH} 4.0)$ using a microfluidizer. The dialyzed and concentrated liposome preparations resulted in $80-100 \mathrm{~nm}$ in size and more than $90 \%$ encapsulation (231).

The mRNA-based liposomes were also tested to induce humoral responses against influenza A virus in a mouse model. Lipid nanoparticles were engineered to deliver a synthetic, selfamplifying mRNA encoding seasonal influenza HA and tested their immunogenicity in mouse model. This mRNA-based vaccine elicited an immune response comparable to that obtained with the licensed influenza subunit vaccine and all the immunized animals showed HA inhibition and neutralizing antibody titers against the virus 14 days after the second immunization (232). In another study, the immunogenicity of lipid nanoparticles encapsulating a modified non-replicating mRNA encoding influenza H10 HA was tested in rhesus macaques. This study showed that anti-HA protective antibody titers and MHC class II-restricted H10-specific $\mathrm{T}$ cell response were elicited after two intradermal or intramuscular immunizations. Moreover, this study provided evidences on cells and mechanisms responsible for the efficacy of mRNA vaccinations: following the administration of mRNA-liposomes, DCs, monocytes, and neutrophils were recruited to the site of immunization and draining LNs, but only DCs and monocytes internalized liposomes, produced virus antigens, translating the mRNA, and upregulated costimulatory molecules. This in vivo antigen production and activation of APCs lead to the priming of a potent H10-specific MHC class II-restricted T cell response (233). The superiority of liposome encapsulation versus other delivery systems of mRNA was stressed by the group of Bogers and colleagues, who proved the immunogenicity and the safety of cationic liposomes formulated with the mRNA encoding for a clade $\mathrm{C}$ envelope glycoprotein of HIV in rhesus macaques. This formulation elicited a cellular immune response and a neutralizing antibody response stronger than those elicited by self-amplifying mRNA encapsulated in a viral replicon particle or by a recombinant HIV envelope protein formulated with MF59 adjuvant (234).

\section{ENGINEERING MULTIROLE LIPOSOMES ABLE TO DELIVER DRUGS, ANTIGENS, ADJUVANTS, AND/OR LIPID SECOND MESSENGERS AS AN ADDITIONAL TOOL TO CONTRAST INFECTIOUS DISEASES}

Infectious diseases are the leading causes of morbidity and mortality worldwide and the increasing incidence of treatmentresistant infections has become a major global concern for their epidemic potential (235). In 2016, WHO reported $6 \times 10^{5}$ new cases of TB with resistance to rifampicin, the most effective firstline anti-TB drug, of which $4.9 \times 10^{5}$ had MDR TB and about 9.5\% of MDR-TB cases have additional drug resistance and were defined XDR-TB. ${ }^{1}$ Moreover, $2.3 \times 10^{4}$ in $\mathrm{US}^{2}$ and $2.5 \times 10^{4}$ deaths in Europe $^{3}$ are attributable each year to infections caused by Gram-positive (Streptococcus penumoniae, Staphylococcus aureus), and Gram-negative (Pseudomonas spp., Acinetobacter spp., and Enterobacteriaceae) bacteria with multidrug- or panantibiotic resistance. As a consequence, the development of novel antimicrobial agents and/or other immunotherapeutic options represents a global health priority (236). To this regard, several therapeutic strategies, targeting the host rather than the pathogen, have been proposed and are under development as adjunctive treatments, in particular for MDR TB (235). Examples of host-directed therapies are the reinfusion of in vitro expanded pathogen-specific autologous $\mathrm{T}$ cells, the administration of micronutrients, antimicrobial peptides, or immune modulators and therapeutic vaccines (235).

Liposomes may offer several advantages in the design of novel pathogen- or host-directed therapies and vaccines, since these nanoparticles can be engineered as delivery system as well as immune modulators. In clinical applications, liposomal drugs have been proven their ability to "passively" accumulate at sites of increased vasculature permeability and for their ability to reduce the side effects of the encapsulated drugs in comparison to free drugs (237). This has resulted in an overall increase in TI, so that liposomal drug delivery has become an established technology platform in some circumstances and has gained considerable clinical acceptance (26). A new frontier in liposomebased approaches against infectious diseases may be envisaged if liposomes are designed as carrier of antigens or drugs in addition to molecules with immunomodulatory functions (Figure 4). For example, antigen-loaded liposome carrying different PAMPs inside or exposed on their outer surface leaflet, would target plasma membrane-associated or intracellular pattern-recognition

${ }^{1}$ http://www.who.int/tb/publications/global_report/en/. ${ }^{2}$ https://www.cdc.gov/drugresistance/threat-report-2013/index.html.

${ }^{3}$ http://www.ema.europa.eu/ema/index.jsp?curl=pages/news_and_events/ news/2009/11/news_detail_000044.jsp\&mid=WC0b01ac058004d5c1. 


\section{Drug/Antigen delivery}

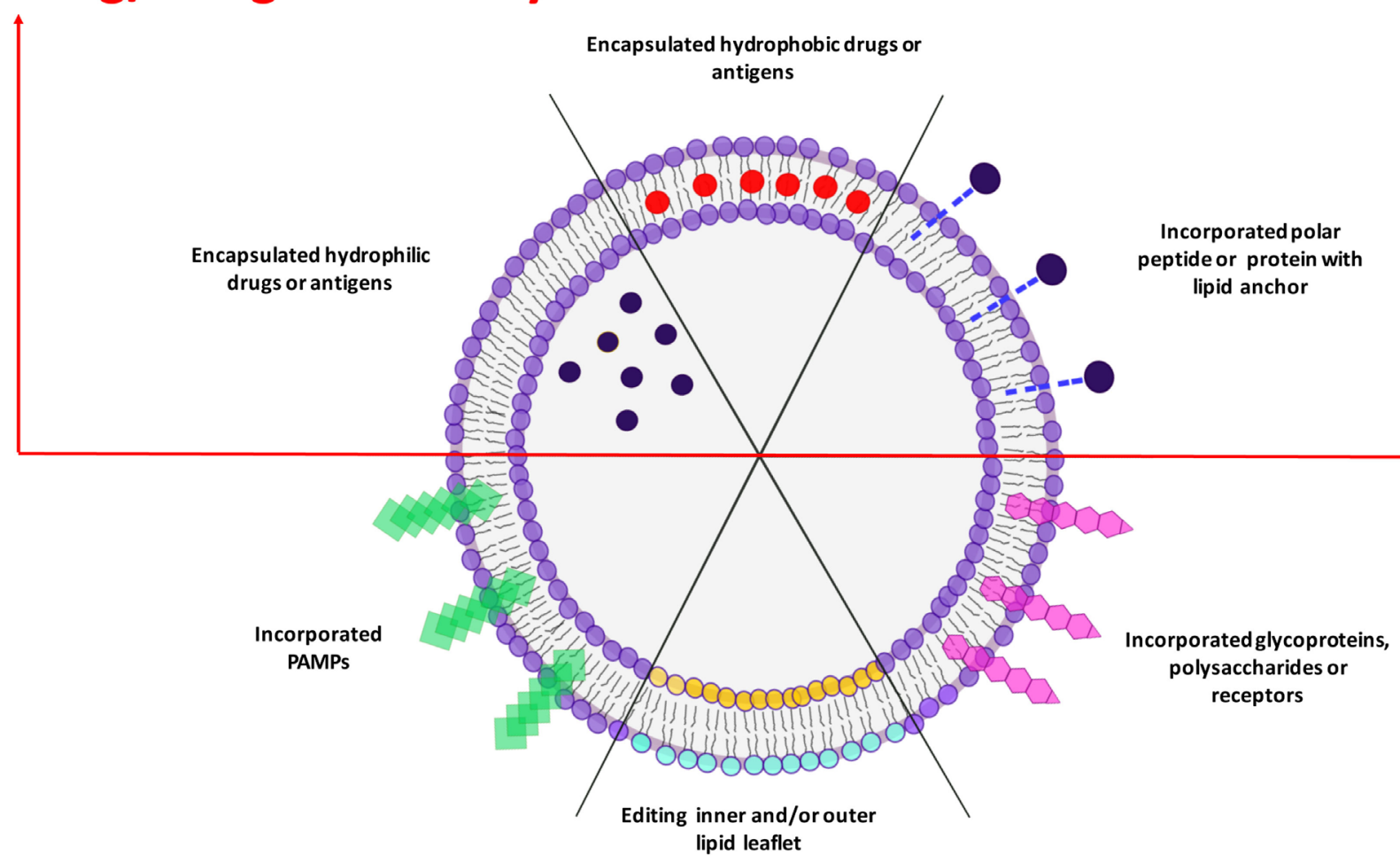

Hydrophobic drugs or antigens

FIGURE 4 | Plasticity of liposome technology. Liposome technology allows combining the selective delivery of drugs or antigens (upper side) with immunomodulatory functions played by incorporated pathogen-associated molecular patterns (PAMPs) or selected bioactive phospholipids (lower side). The simultaneous delivery of antigen/drugs and immunomodulatory molecules makes liposomes a versatile platform to design different therapeutic or prophylactic tools to face pathogen-specific strategies.

receptors, respectively, and consequently activate APC to secrete different cytokines, which in turn may drive diverse polarizations of the antigen-specific adaptive immune response (11). It is also possible to engineer asymmetric liposomes that express different lipids at the outer and inner membrane leaflet $(15,136,238)$. In this regard, PS may be included in the constitutive lipids of the outer liposome leaflet to target specific cells, like macrophages, whereas lipid second messengers, such as PA or PI(3)P, can be incorporated in the inner leaflet to be delivered to the cell microvesicular system to modulate intracellular endosome trafficking (15, 136, 238). Pathogens may target host lipid metabolism and PL maturation as an intracellular survival strategy and mechanism of immunoevasion (14, 144-146, 148-152, 238-241). The growing evidences for a crucial role played by lipid second messengers in PL biogenesis $(91-94,129)$ opens new therapeutic possibilities for the reactivation/enhancement of antimicrobial innate immune response with the specific intracellular delivery of lipid second messengers taking advantage of the liposome technology. Since scaling up, stability and regulatory issues are commonly successfully addressed, the clinical availability of novel liposome formulations can be foreseen in the near future. The possibility to enhance/correct specific molecular pathways by lipid second messengers, used for liposome scaffold, may represent a further added value to the plethora of different possibilities offered by liposomes technology and a possible novel host-directed therapy to face the global emergence of antimicrobial resistance.

\section{AUTHOR CONTRIBUTIONS}

All authors made substantial contributions to the conception or design of the work. NP, SM, and FS contributed to the acquisition, analysis, interpretation of data for the work. NP and FS drew the figures. RN and MF wrote the work. All authors revised critically the work for important intellectual content, gave final approval of the version to be published, and agreed to be accountable for all aspects of the work in ensuring that questions related to the accuracy or integrity of any part of the work are appropriately investigated and resolved. 


\section{ACKNOWLEDGMENTS}

Authors would like to thank Raffaela Teloni for technical assistance.

\section{FUNDING}

Research supported by (i) the Horizon 2020 Programme of European Commission, grant "EMI-TB"; Eliciting Mucosal Immunity against Tuberculosis-grant \# 643558; and

\section{REFERENCES}

1. Abu Lila AS, Ishida T. Liposomal delivery systems: design optimization and current applications. Biol Pharm Bull (2017) 40(1):1-10. doi:10.1248/bpb.b16-00624

2. Bozzuto G, Molinari A. Liposomes as nanomedical devices. Int J Nanomedicine (2015) 10:975-99. doi:10.2147/IJN.S68861

3. Bulbake U, Doppalapudi S, Kommineni N, Khan W. Liposomal formulations in clinical use: an updated review. Pharmaceutics (2017) 9(2):1-33. doi:10.3390/pharmaceutics9020012

4. Mufamadi MS, Pillay V, Choonara YE, Du Toit LC, Modi G, Naidoo D, et al. A review on composite liposomal technologies for specialized drug delivery. J Drug Deliv (2011) 2011:939851. doi:10.1155/2011/939851

5. Immordino ML, Dosio F, Cattel L. Stealth liposomes: review of the basic science, rationale, and clinical applications, existing and potential. Int J Nanomedicine (2006) 1(3):297-315

6. Damen J, Regts J, Scherphof G. Transfer and exchange of phospholipid between small unilamellar liposomes and rat plasma high densitylipoproteins. Dependence on cholesterol content and phospholipid composition. Biochim Biophys Acta (1981) 665(3):538-45. doi:10.1016/0005-2760(81)90268-X

7. Torchilin VP. Recent advances with liposomes as pharmaceutical carriers. Nat Rev Drug Discov (2005) 4(2):145-60. doi:10.1038/nrd1632

8. Manjappa AS, Chaudhari KR, Venkataraju MP, Dantuluri P, Nanda B, Sidda C, et al. Antibody derivatization and conjugation strategies: application in preparation of stealth immunoliposome to target chemotherapeutics to tumor. J Control Release (2011) 150(1):2-22. doi:10.1016/j. jconrel.2010.11.002

9. Lu Y, Sun W, Gu Z. Stimuli-responsive nanomaterials for therapeutic protein delivery. J Control Release (2014) 194:1-19. doi:10.1016/j.jconrel.2014.08.015

10. Li L, ten Hagen TL, Schipper D, Wijnberg TM, van Rhoon GC, Eggermont AM, et al. Triggered content release from optimized stealth thermosensitive liposomes using mild hyperthermia. J Control Release (2010) 143(2):274-9. doi:10.1016/j.jconrel.2010.01.006

11. Perrie Y, Crofts F, Devitt A, Griffiths HR, Kastner E, Nadella V. Designing liposomal adjuvants for the next generation of vaccines. Adv Drug Deliv Rev (2016) 99(Pt A):85-96. doi:10.1016/j.addr.2015.11.005

12. Schwendener RA. Liposomes as vaccine delivery systems: a review of the recent advances. Ther Adv Vaccines (2014) 2(6):159-82. doi: $10.1177 / 2051013614541440$

13. Bernasconi V, Norling K, Bally M, Hook F, Lycke NY. Mucosal vaccine development based on liposome technology. J Immunol Res (2016) 2016:5482087. doi:10.1155/2016/5482087

14. Steinberg BE, Grinstein S. Pathogen destruction versus intracellular survival: the role of lipids as phagosomal fate determinants. JClin Invest (2008) 118(6):2002-11. doi:10.1172/JCI35433

15. Poerio N, Bugli F, Taus F, Santucci MB, Rodolfo C, Cecconi F, et al. Liposomes loaded with bioactive lipids enhance antibacterial innate immunity irrespective of drug resistance. Sci Rep (2017) 7:45120. doi:10.1038/srep45120

16. Peetla C, Stine A, Labhasetwar V. Biophysical interactions with model lipid membranes: applications in drug discovery and drug delivery. Mol Pharm (2009) 6(5):1264-76. doi:10.1021/mp9000662

17. Michot JM, Seral C, Van Bambeke F, Mingeot-Leclercq MP, Tulkens PM. Influence of efflux transporters on the accumulation and efflux of four quinolones (ciprofloxacin, levofloxacin, garenoxacin, and moxifloxacin) in J774 macrophages. Antimicrob Agents Chemother (2005) 49(6):2429-37. doi:10.1128/AAC.49.6.2429-2437.2005
"TBVAC2020; Advancing novel and promising TB vaccine candidates from discovery to preclinical and early clinical development" - grant\# 643381; (ii) Italian Foundation for Cystic Fibrosis, "Preclinical study of a host-directed therapy based on Metformin and bioactive liposomes for the control of multidrug-resistant $P$. aeruginosa infection"-grant \#14/2017; (iii) Italian Foundation for multiple sclerosis, grant \#2016/R/22; and (iv) Ministero della Salute Italiana, Ricerca Finalizzata grant: "Nanotechnology for the multiplex diagnosis of infectious diseases"-grant\# PE-2011-02346849.

18. Bensikaddour H, Snoussi K, Lins L, Van Bambeke F, Tulkens PM, Brasseur $\mathrm{R}$, et al. Interactions of ciprofloxacin with DPPC and DPPG: fluorescence anisotropy, ATR-FTIR and 31P NMR spectroscopies and conformational analysis. Biochim Biophys Acta (2008) 1778(11):2535-43. doi:10.1016/j. bbamem.2008.08.015

19. Yang NJ, Hinner MJ. Getting across the cell membrane: an overview for small molecules, peptides, and proteins. Methods Mol Biol (2015) 1266:29-53. doi:10.1007/978-1-4939-2272-7_3

20. Bangham AD, Standish MM, Watkins JC. Diffusion of univalent ions across the lamellae of swollen phospholipids. J Mol Biol (1965) 13(1):238-52 doi:10.1016/S0022-2836(65)80093-6

21. Deamer DW. From "banghasomes" to liposomes: a memoir of Alec Bangham, 1921-2010. FASEB J (2010) 24(5):1308-10. doi:10.1096/fj.10-0503

22. BatzriS,KornED.Singlebilayerliposomespreparedwithoutsonication.Biochim Biophys Acta (1973) 298(4):1015-9. doi:10.1016/0005-2736(73)90408-2

23. Gregoriadis G. The carrier potential of liposomes in biology and medicine (second of two parts). N Engl J Med (1976) 295(14):765-70. doi:10.1056/ NEJM197609302951406

24. Gregoriadis $\mathrm{G}$. The carrier potential of liposomes in biology and medicine (first of two parts). N Engl J Med (1976) 295(13):704-10. doi:10.1056/ NEJM197609232951305

25. Kobayashi T, Tsukagoshi S, Sakurai Y. Enhancement of the cancer chemotherapeutic effect of cytosine arabinoside entrapped in liposomes on mouse leukemia L-1210. Gann (1975) 66(6):719-20.

26. Allen TM, Cullis PR. Liposomal drug delivery systems: from concept to clinical applications. Adv Drug Deliv Rev (2013) 65(1):36-48. doi:10.1016/j. addr.2012.09.037

27. Uziely B, Jeffers S, Isacson R, Kutsch K, Wei-Tsao D, Yehoshua Z, et al. Liposomal doxorubicin: antitumor activity and unique toxicities during two complementary phase I studies. J Clin Oncol (1995) 13(7):1777-85. doi:10.1200/JCO.1995.13.7.1777

28. Abuchowski A, McCoy JR, Palczuk NC, van Es T, Davis FF. Effect of covalent attachment of polyethylene glycol on immunogenicity and circulating life of bovine liver catalase. J Biol Chem (1977) 252(11):3582-6.

29. Papahadjopoulos D, Allen TM, Gabizon A, Mayhew E, Matthay K, Huang SK, et al. Sterically stabilized liposomes: improvements in pharmacokinetics and antitumor therapeutic efficacy. Proc Natl Acad Sci U S A (1991) 88(24):11460-4. doi:10.1073/pnas.88.24.11460

30. Allen TM, Hansen C. Pharmacokinetics of stealth versus conventional liposomes: effect of dose. Biochim Biophys Acta (1991) 1068(2):133-41. doi:10.1016/0005-2736(91)90201-I

31. James ND, Coker RJ, Tomlinson D, Harris JR, Gompels M, Pinching AJ, et al. Liposomal doxorubicin (Doxil): an effective new treatment for Kaposi's sarcoma in AIDS. Clin Oncol (R Coll Radiol) (1994) 6(5):294-6. doi:10.1016/ S0936-6555(05)80269-9

32. Eloy JO, Petrilli R, Trevizan LNF, Chorilli M. Immunoliposomes: a review on functionalization strategies and targets for drug delivery. Colloids Surf B Biointerfaces (2017) 159:454-67. doi:10.1016/j.colsurfb.2017.07.085

33. Petrilli R, Eloy JO, Lee RJ, Lopez RFV. Preparation of immunoliposomes by direct coupling of antibodies based on a thioether bond. Methods Mol Biol (2018) 1674:229-37. doi:10.1007/978-1-4939-7312-5_19

34. Spragg DD, Alford DR, Greferath R, Larsen CE, Lee KD, Gurtner GC, et al. Immunotargeting of liposomes to activated vascular endothelial cells: a strategy for site-selective delivery in the cardiovascular system. Proc Natl Acad Sci U S A (1997) 94(16):8795-800. doi:10.1073/pnas.94.16.8795 
35. Yang T, Choi MK, Cui FD, Kim JS, Chung SJ, Shim CK, et al. Preparation and evaluation of paclitaxel-loaded PEGylated immunoliposome. J Control Release (2007) 120(3):169-77. doi:10.1016/j.jconrel.2007.05.011

36. Pan X, Wu G, Yang W, Barth RF, Tjarks W, Lee RJ. Synthesis of cetuximab-immunoliposomes via a cholesterol-based membrane anchor for targeting of EGFR. Bioconjug Chem (2007) 18(1):101-8. doi:10.1021/bc060174r

37. Eskandari F, Talesh GA, Parooie M, Jaafari MR, Khamesipour A, Saberi $\mathrm{Z}$, et al. Immunoliposomes containing soluble Leishmania antigens (SLA) as a novel antigen delivery system in murine model of leishmaniasis. Exp Parasitol (2014) 146:78-86. doi:10.1016/j.exppara.2014.08.016

38. Rabenhold M, Steiniger F, Fahr A, Kontermann RE, Ruger R. Bispecific single-chain diabody-immunoliposomes targeting endoglin (CD105) and fibroblast activation protein (FAP) simultaneously. J Control Release (2015) 201:56-67. doi:10.1016/j.jconrel.2015.01.022

39. Lopez-Berestein G, Fainstein V, Hopfer R, Mehta K, Sullivan MP, Keating $\mathrm{M}$, et al. Liposomal Amphotericin B for the treatment of systemic fungal infections in patients with cancer: a preliminary study. J Infect Dis (1985) 151(4):704-10. doi:10.1093/infdis/151.4.704

40. Lee WH, Loo CY, Traini D, Young PM. Nano- and micro-based inhaled drug delivery systems for targeting alveolar macrophages. Expert Opin Drug Deliv (2015) 12(6):1009-26. doi:10.1517/17425247.2015.1039509

41. Ternullo S, de Weerd L, Mari Holsaeter A, Eide Flaten G, Skalko-Basnet N. Going skin deep: a direct comparison of penetration potential of lipid-based nanovesicles on the isolated perfused human skin flap model. Eur J Pharm Biopharm (2017) 121:14-23. doi:10.1016/j.ejpb.2017.09.006

42. Malam Y, Loizidou M, Seifalian AM. Liposomes and nanoparticles: nanosized vehicles for drug delivery in cancer. Trends Pharmacol Sci (2009) 30(11):592-9. doi:10.1016/j.tips.2009.08.004

43. Balazsovits JA, Mayer LD, Bally MB, Cullis PR, McDonell M, Ginsberg RS, et al. Analysis of the effect of liposome encapsulation on the vesicant properties, acute and cardiac toxicities, and antitumor efficacy of doxorubicin. Cancer Chemother Pharmacol (1989) 23(2):81-6. doi:10.1007/BF00273522

44. Forssen EA, Coulter DM, Proffitt RT. Selective in vivo localization of daunorubicin small unilamellar vesicles in solid tumors. Cancer Res (1992) 52(12):3255-61

45. Kim S, Chatelut E, Kim JC, Howell SB, Cates C, Kormanik PA, et al. Extended CSF cytarabine exposure following intrathecal administration of DTC 101. J Clin Oncol (1993) 11(11):2186-93. doi:10.1200/JCO.1993.11.11.2186

46. Meyers PA, Schwartz CL, Krailo MD, Healey JH, Bernstein ML, Betcher D, et al. Osteosarcoma: the addition of muramyl tripeptide to chemotherapy improves overall survival - a report from the Children's Oncology Group. J Clin Oncol (2008) 26(4):633-8. doi:10.1200/JCO.2008.14.0095

47. Krishna R, Webb MS, St Onge G, Mayer LD. Liposomal and nonliposomal drug pharmacokinetics after administration of liposome-encapsulated vincristine and their contribution to drug tissue distribution properties. J Pharmacol Exp Ther (2001) 298(3):1206-12.

48. Wang-Gillam A, Li CP, Bodoky G, Dean A, Shan YS, Jameson G, et al. Nanoliposomal irinotecan with fluorouracil and folinic acid in metastatic pancreatic cancer after previous gemcitabine-based therapy (NAPOLI-1): a global, randomised, open-label, phase 3 trial. Lancet (2016) 387(10018):54557. doi:10.1016/S0140-6736(15)00986-1

49. Lister J. Amphotericin B lipid complex (Abelcet) in the treatment of invasive mycoses: the North American experience. Eur J Haematol Suppl (1996) 57:18-23.

50. Adler-Moore J, Proffitt RT. AmBisome: liposomal formulation, structure, mechanism of action and pre-clinical experience. J Antimicrob Chemother (2002) 49(Suppl 1):21-30. doi:10.1093/jac/49.suppl_1.21

51. Carvalheiro M, Esteves MA, Santos-Mateus D, Lopes RM, Rodrigues MA, Eleuterio $\mathrm{CV}$, et al. Hemisynthetic trifluralin analogues incorporated in liposomes for the treatment of leishmanial infections. Eur J Pharm Biopharm (2015) 93:346-52. doi:10.1016/j.ejpb.2015.04.018

52. da Costa-Silva TA, Galisteo AJ Jr, Lindoso JA, Barbosa LR, Tempone AG. Nanoliposomal buparvaquone immunomodulates leishmania infantum-infected macrophages and is highly effective in a murine model. Antimicrob Agents Chemother (2017) 61(4):e02297-16. doi:10.1128/AAC.02297-16

53. Moles E, Galiano S, Gomes A, Quiliano M, Teixeira C, Aldana I, et al. ImmunoPEGliposomes for the targeted delivery of novel lipophilic drugs to red blood cells in a falciparum malaria murine model. Biomaterials (2017) 145:178-91. doi:10.1016/j.biomaterials.2017.08.020
54. Rajendran V, Rohra S, Raza M, Hasan GM, Dutt S, Ghosh PC. Stearylamine liposomal delivery of monensin in combination with free artemisinin eliminates blood stages of Plasmodium falciparum in culture and P. berghei infection in murine malaria. Antimicrob Agents Chemother (2015) 60(3):1304-18. doi:10.1128/AAC.01796-15

55. Ibrahim S, Tagami T, Ozeki T. Effective-loading of platinum-chloroquine into PEGylated neutral and cationic liposomes as a drug delivery system for resistant malaria parasites. Biol Pharm Bull (2017) 40(6):815-23. doi:10.1248/ bpb.b16-00914

56. Agrawal AK, Singhal A, Gupta CM. Functional drug targeting to erythrocytes in vivo using antibody bearing liposomes as drug vehicles. Biochem Biophys Res Commun (1987) 148(1):357-61. doi:10.1016/0006-291X(87)91118-1

57. Tagami T, Yanai H, Terada Y, Ozeki T. Evaluation of phosphatidylserine-specific peptide-conjugated liposomes using a model system of malaria-infected erythrocytes. Biol Pharm Bull (2015) 38(10):1649-51. doi:10.1248/bpb. b15-00310

58. Guo J, Waknine-Grinberg JH, Mitchell AJ, Barenholz Y, Golenser J. Reduction of experimental cerebral malaria and its related proinflammatory responses by the novel liposome-based beta-methasone nanodrug. Biomed Res Int (2014) 2014:292471. doi:10.1155/2014/292471

59. Tomiotto-Pellissier F, Miranda-Sapla MM, Machado LF, Bortoleti B, Sahd CS, Chagas AF, et al. Nanotechnology as a potential therapeutic alternative for schistosomiasis. Acta Trop (2017) 174:64-71. doi:10.1016/j. actatropica.2017.06.025

60. Frezza TF, de Souza AL, Prado CC, de Oliveira CN, Gremiao MP, Giorgio $S$, et al. Effectiveness of hyperbaric oxygen for experimental treatment of schistosomiasis mansoni using praziquantel-free and encapsulated into liposomes: assay in adult worms and oviposition. Acta Trop (2015) 150:182-9. doi:10.1016/j.actatropica.2015.07.022

61. Faber K, Zorzi GK, Brazil NT, Rott MB, Teixeira HF. siRNA-loaded liposomes: inhibition of encystment of Acanthamoeba and toxicity on the eye surface. Chem Biol Drug Des (2017) 90(3):406-16. doi:10.1111/ cbdd. 12958

62. Islan GA, Duran M, Cacicedo ML, Nakazato G, Kobayashi RKT, Martinez DST, et al. Nanopharmaceuticals as a solution to neglected diseases: is it possible? Acta Trop (2017) 170:16-42. doi:10.1016/j.actatropica.2017.02.019

63. Pandey R, Khuller GK. Solid lipid particle-based inhalable sustained drug delivery system against experimental tuberculosis. Tuberculosis (Edinb) (2005) 85(4):227-34. doi:10.1016/j.tube.2004.11.003

64. Pandey R, Khuller GK. Antitubercular inhaled therapy: opportunities, progress and challenges. JAntimicrob Chemother (2005) 55(4):430-5. doi:10.1093/jac/dki027

65. Parumasivam T, Chang RY, Abdelghany S, Ye TT, Britton WJ, Chan HK. Dry powder inhalable formulations for anti-tubercular therapy. Adv Drug Deliv Rev (2016) 102:83-101. doi:10.1016/j.addr.2016.05.011

66. Rawal T, Parmar R, Tyagi RK, Butani S. Rifampicin loaded chitosan nanoparticle dry powder presents an improved therapeutic approach for alveolar tuberculosis. Colloids Surf B Biointerfaces (2017) 154:321-30. doi:10.1016/j. colsurfb.2017.03.044

67. Parumasivam T, Leung SS, Quan DH, Triccas JA, Britton WJ, Chan HK. Rifapentine-loaded PLGA microparticles for tuberculosis inhaled therapy: preparation and in vitro aerosol characterization. Eur J Pharm Sci (2016) 88:1-11. doi:10.1016/j.ejps.2016.03.024

68. Pham DD, Fattal E, Tsapis N. Pulmonary drug delivery systems for tuberculosis treatment. Int J Pharm (2015) 478(2):517-29. doi:10.1016/j. ijpharm.2014.12.009

69. Justo OR, Moraes AM. Incorporation of antibiotics in liposomes designed for tuberculosis therapy by inhalation. Drug Deliv (2003) 10(3):201-7. doi: $10.1080 / 713840401$

70. Zaru M, Sinico C, De Logu A, Caddeo C, Lai F, Manca ML, et al. Rifampicin-loaded liposomes for the passive targeting to alveolar macrophages: in vitro and in vivo evaluation. J Liposome Res (2009) 19(1):68-76. doi:10.1080/08982100802610835

71. Mehanna MM, Mohyeldin SM, Elgindy NA. Respirable nanocarriers as a promising strategy for antitubercular drug delivery. J Control Release (2014) 187:183-97. doi:10.1016/j.jconrel.2014.05.038

72. Rojanarat W, Nakpheng T, Thawithong E, Yanyium N, Srichana T. Inhaled pyrazinamide proliposome for targeting alveolar macrophages. Drug Deliv (2012) 19(7):334-45. doi:10.3109/10717544.2012.721144 
73. Rojanarat W, Changsan N, Tawithong E, Pinsuwan S, Chan HK, Srichana T. Isoniazid proliposome powders for inhalation-preparation, characterization and cell culture studies. Int J Mol Sci (2011) 12(7):4414-34. doi:10.3390/ ijms12074414

74. Patil-Gadhe AA, Kyadarkunte AY, Pereira M, Jejurikar G, Patole MS, Risbud A, et al. Rifapentine-proliposomes for inhalation: in vitro and in vivo toxicity. Toxicol Int (2014) 21(3):275-82. doi:10.4103/0971-6580.155361

75. Patil-Gadhe A, Pokharkar V. Single step spray drying method to develop proliposomes for inhalation: a systematic study based on quality by design approach. Pulm Pharmacol Ther (2014) 27(2):197-207. doi:10.1016/j. pupt.2013.07.006

76. Pramod K, Tahir MA, Charoo NA, Ansari SH, Ali J. Pharmaceutical product development: a quality by design approach. Int J Pharm Investig (2016) 6(3):129-38. doi:10.4103/2230-973X.187350

77. EMA. Reflection Paper on the Data Requirements for Intravenous Liposomal Products Developed with Reference to an Innovator Liposomal Product. EMA/ CHMP/806058/2009/Rev 02. London, UK: European Medicines Agency (2013).

78. FDA. Liposome Drug Products Chemistry, Manufacturing, and Controls; Human Pharmacokinetics and Bioavailability; and Labeling Documentation Guidance for Industry. Pharmaceutical Quality/CMC (Revision I). Silver Spring, MD: Food and Drug Administration (2015).

79. Kouchak M, Malekahmadi M, Bavarsad N, Saki Malehi A, Andishmand L. Dorzolamide nanoliposome as a long action ophthalmic delivery system in open angle glaucoma and ocular hypertension patients. Drug Dev Ind Pharm (2017) (9):1-16. doi:10.1080/03639045.2017.1386196

80. Zhang R, Qian J, Li X, Yuan Y. Treatment of experimental autoimmune uveoretinitis with intravitreal injection of infliximab encapsulated in liposomes. Br JOphthalmol (2017) 101(12):1731-8. doi:10.1136/ bjophthalmol-2016-310044

81. Bowles EA, Feys D, Ercal N, Sprague RS. Liposomal-delivery of phosphodiesterase 5 inhibitors augments UT-15C-stimulated ATP release from human erythrocytes. Biochem Biophys Rep (2017) 12:114-9. doi:10.1016/j. bbrep.2017.09.002

82. Kumar L, Verma S, Vaidya B. Liposomes for the delivery of streptokinase. Ther Deliv (2017) 8(10):855-66. doi:10.4155/tde-2017-0026

83. Shin M, Snyder HW, Donvito G, Schurman LD, Fox TE, Lichtman AH, et al. Liposomal delivery of diacylglycerol lipase-beta inhibitors to macrophages dramatically enhances selectivity and efficacy in vivo. Mol Pharm (2017). doi:10.1021/acs.molpharmaceut.7b00657

84. Malik O, Kaye AD, Kaye A, Belani K, Urman RD. Emerging roles of liposomal bupivacaine in anesthesia practice. J Anaesthesiol Clin Pharmacol (2017) 33(2):151-6. doi:10.4103/joacp.JOACP_375_15

85. Beiranvand S, Moradkhani MR. Bupivacaine versus liposomal bupivacaine for pain control. Drug Res (Stuttg) (2017). doi:10.1055/s-0043-121142

86. Abdel-Mottaleb MM, Moulari B, Beduneau A, Pellequer Y, Lamprecht A. Nanoparticles enhance therapeutic outcome in inflamed skin therapy. Eur JPharm Biopharm (2012) 82(1):151-7. doi:10.1016/j.ejpb.2012. 06.006

87. Zakrewsky M, Kumar S, Mitragotri S. Nucleic acid delivery into skin for the treatment of skin disease: proofs-of-concept, potential impact, and remaining challenges. J Control Release (2015) 219:445-56. doi:10.1016/j. jconrel.2015.09.017

88. Pujol-Autonell I, Mansilla MJ, Rodriguez-Fernandez S, Cano-Sarabia M, Navarro-Barriuso J, Ampudia RM, et al. Liposome-based immunotherapy against autoimmune diseases: therapeutic effect on multiple sclerosis. Nanomedicine (Lond) (2017) 12(11):1231-42. doi:10.2217/nnm2016-0410

89. Pang L, Macauley MS, Arlian BM, Nycholat CM, Paulson JC. Encapsulating an immunosuppressant enhances tolerance induction by Siglec-engaging tolerogenic liposomes. Chembiochem (2017) 18(13):1226-33. doi:10.1002/ cbic. 201600702

90. Perri V, Pellegrino M, Ceccacci F, Scipioni A, Petrini S, Gianchecchi E, et al. Use of short interfering RNA delivered by cationic liposomes to enable efficient down-regulation of PTPN22 gene in human T lymphocytes. PLoS One (2017) 12(4):e0175784. doi:10.1371/journal.pone.0175784

91. Yeung T, Ozdamar B, Paroutis P, Grinstein S. Lipid metabolism and dynamics during phagocytosis. Curr Opin Cell Biol (2006) 18(4):429-37. doi:10.1016/j. ceb.2006.06.006
92. Yeung T, Grinstein S. Lipid signaling and the modulation of surface charge during phagocytosis. Immunol Rev (2007) 219:17-36. doi:10.1111/j.1600-065X.2007.00546.x

93. Bohdanowicz M, Grinstein S. Role of phospholipids in endocytosis, phagocytosis, and macropinocytosis. Physiol Rev (2013) 93(1):69-106. doi:10.1152/ physrev.00002.2012

94. Levin R, Grinstein S, Schlam D. Phosphoinositides in phagocytosis and macropinocytosis. Biochim Biophys Acta (2015) 1851(6):805-23. doi:10.1016/j. bbalip.2014.09.005

95. Jenkins GH, Fisette PL, Anderson RA. Type I phosphatidylinositol 4-phosphate 5 -kinase isoforms are specifically stimulated by phosphatidic acid. J Biol Chem (1994) 269(15):11547-54.

96. Levin R, Grinstein S, Canton J. The life cycle of phagosomes: formation, maturation, and resolution. Immunol Rev (2016) 273(1):156-79. doi:10.1111/ imr.12439

97. Cox D, Tseng CC, Bjekic G, Greenberg S. A requirement for phosphatidylinositol 3-kinase in pseudopod extension. J Biol Chem (1999) 274(3):1240-7. doi:10.1074/jbc.274.3.1240

98. Falasca M, Logan SK, Lehto VP, Baccante G, Lemmon MA, Schlessinger J. Activation of phospholipase $\mathrm{C}$ gamma by PI 3-kinase-induced $\mathrm{PH}$ domain-mediated membrane targeting. EMBO J (1998) 17(2):414-22. doi:10.1093/emboj/17.2.414

99. Bohdanowicz M, Schlam D, Hermansson M, Rizzuti D, Fairn GD, Ueyama $T$, et al. Phosphatidic acid is required for the constitutive ruffling and macropinocytosis of phagocytes. Mol Biol Cell (2013) 24(11):1700-12, S1-7. doi:10.1091/mbc.E12-11-0789

100. Flannagan RS, Cosio G, Grinstein S. Antimicrobial mechanisms of phagocytes and bacterial evasion strategies. Nat Rev Microbiol (2009) 7(5):355-66. doi:10.1038/nrmicro2128

101. Lemmon MA. Phosphoinositide recognition domains. Traffic (2003) 4(4):201-13. doi:10.1034/j.1600-0854.2004.00071.x

102. Ktistakis NT, Delon C, Manifava M, Wood E, Ganley I, Sugars JM. Phospholipase D1 and potential targets of its hydrolysis product, phosphatidic acid. Biochem Soc Trans (2003) 31(Pt 1):94-7. doi:10.1042/bst0310094

103. Albanesi J, Wang H, Sun HQ, Levine B, Yin H. GABARAP-mediated targeting of PI4K2A/PI4KIIalpha to autophagosomes regulates PtdIns4P-dependent autophagosome-lysosome fusion. Autophagy (2015) 11(11):2127-9. doi:10.1080/15548627.2015.1093718

104. DoveSK, DongK, KobayashiT, WilliamsFK, MichellRH.Phosphatidylinositol 3,5-bisphosphate and Fablp/PIKfyve underPPIn endo-lysosome function. Biochem J (2009) 419(1):1-13. doi:10.1042/BJ20081950

105. Boal F, Mansour R, Gayral M, Saland E, Chicanne G, Xuereb JM, et al. TOM1 is a PI5P effector involved in the regulation of endosomal maturation. J Cell Sci (2015) 128(4):815-27. doi:10.1242/jcs.166314

106. Gaullier JM, Simonsen A, D’Arrigo A, Bremnes B, Stenmark H, Aasland R. FYVE fingers bind PtdIns(3)P. Nature (1998) 394(6692):432-3. doi: $10.1038 / 28767$

107. Kanai F, Liu H, Field SJ, Akbary H, Matsuo T, Brown GE, et al. The PX domains of p47phox and p40phox bind to lipid products of PI(3)K. Nat Cell Biol (2001) 3(7):675-8. doi:10.1038/35083070

108. Hirst J, Motley A, Harasaki K, Peak Chew SY, Robinson MS. EpsinR: an ENTH domain-containing protein that interacts with AP-1. Mol Biol Cell (2003) 14(2):625-41. doi:10.1091/mbc.E02-09-0552

109. Levine TP, Munro S. Targeting of Golgi-specific pleckstrin homology domains involves both PtdIns 4-kinase-dependent and -independent components. Curr Biol (2002) 12(9):695-704. doi:10.1016/ S0960-9822(02)00779-0

110. Gozani O, Karuman P, Jones DR, Ivanov D, Cha J, Lugovskoy AA, et al. The PHD finger of the chromatin-associated protein ING2 functions as a nuclear phosphoinositide receptor. Cell (2003) 114(1):99-111. doi:10.1016/ S0092-8674(03)00480-X

111. Itoh T, Koshiba S, Kigawa T, Kikuchi A, Yokoyama S, Takenawa T. Role of the ENTH domain in phosphatidylinositol-4,5-bisphosphate binding and endocytosis. Science (2001) 291(5506):1047-51. doi:10.1126/ science.291.5506.1047

112. Ford MG, Pearse BM, Higgins MK, Vallis Y, Owen DJ, Gibson A, et al. Simultaneous binding of PtdIns(4,5)P2 and clathrin by AP180 in the nucleation of clathrin lattices on membranes. Science (2001) 291(5506):1051-5. doi:10.1126/science.291.5506.1051 
113. Lemmon MA, Ferguson KM, O’Brien R, Sigler PB, Schlessinger J. Specific and high-affinity binding of inositol phosphates to an isolated pleckstrin homology domain. Proc Natl Acad Sci U S A (1995) 92(23):10472-6. doi:10.1073/pnas.92.23.10472

114. Corbalan-Garcia S, Garcia-Garcia J, Rodriguez-Alfaro JA, Gomez-Fernandez JC. A new phosphatidylinositol 4,5-bisphosphate-binding site located in the C2 domain of protein kinase Calpha. J Biol Chem (2003) 278(7):4972-80. doi:10.1074/jbc.M209385200

115. Hamada K, Shimizu T, Matsui T, Tsukita S, Hakoshima T. Structural basis of the membrane-targeting and unmasking mechanisms of the radixin FERM domain. EMBO J (2000) 19(17):4449-62. doi:10.1093/emboj/ 19.17.4449

116. Stolt PC, Jeon H, Song HK, Herz J, Eck MJ, Blacklow SC. Origins of peptide selectivity and phosphoinositide binding revealed by structures of disabled-1 PTB domain complexes. Structure (2003) 11(5):569-79. doi:10.1016/ S0969-2126(03)00068-6

117. Eugster A, Pecheur EI, Michel F, Winsor B, Letourneur F, Friant S. Ent5p is required with Ent3p and Vps27p for ubiquitin-dependent protein sorting into the multivesicular body. Mol Biol Cell (2004) 15(7):3031-41. doi:10.1091/ mbc.E03-11-0793

118. Tsujita $\mathrm{K}$, Itoh $\mathrm{T}$, Ijuin $\mathrm{T}$, Yamamoto A, Shisheva A, Laporte J, et al. Myotubularin regulates the function of the late endosome through the gram domain-phosphatidylinositol 3,5-bisphosphate interaction. JBiol Chem (2004) 279(14):13817-24. doi:10.1074/jbc.M312294200

119. Manna D, Albanese A, Park WS, Cho W. Mechanistic basis of differential cellular responses of phosphatidylinositol 3,4-bisphosphate- and phosphatidylinositol 3,4,5-trisphosphate-binding pleckstrin homology domains. J Biol Chem (2007) 282(44):32093-105. doi:10.1074/jbc.M703517200

120. Lee JS, Kim JH, Jang IH, Kim HS, Han JM, Kazlauskas A, et al. Phosphatidylinositol $(3,4,5)$-trisphosphate specifically interacts with the phox homology domain of phospholipase D1 and stimulates its activity. J Cell Sci (2005) 118(Pt 19):4405-13. doi:10.1242/jcs.02564

121. Di Paolo G, De Camilli P. Phosphoinositides in cell regulation and membrane dynamics. Nature (2006) 443(7112):651-7. doi:10.1038/nature05185

122. Zhao DM, Thornton AM, DiPaolo RJ, Shevach EM. Activated CD4+CD25+ T cells selectively kill B lymphocytes. Blood (2006) 107(10):3925-32. doi:10.1182/blood-2005-11-4502

123. Karathanassis D, Stahelin RV, Bravo J, Perisic O, Pacold CM, Cho W, et al. Binding of the PX domain of p47(phox) to phosphatidylinositol 3,4-bisphosphate and phosphatidic acid is masked by an intramolecular interaction. EMBO J (2002) 21(19):5057-68. doi:10.1093/emboj/cdf519

124. Jose Lopez-Andreo M, Gomez-Fernandez JC, Corbalan-Garcia S. The simultaneous production of phosphatidic acid and diacylglycerol is essential for the translocation of protein kinase Cepsilon to the plasma membrane in RBL-2H3 cells. Mol Biol Cell (2003) 14(12):4885-95. doi:10.1091/mbc. E03-05-0295

125. Matsuo H, Chevallier J, Mayran N, Le Blanc I, Ferguson C, Faure J, et al. Role of LBPA and Alix in multivesicular liposome formation and endosome organization. Science (2004) 303(5657):531-4. doi:10.1126/science. 1092425

126. Wojcik-Piotrowicz K, Kaszuba-Zwoinska J, Rokita E, Thor P. Cell viability modulation through changes of $\mathrm{Ca}(2+)$-dependent signalling pathways. Prog Biophys Mol Biol (2016) 121(1):45-53. doi:10.1016/j.pbiomolbio.2016. 01.004

127. Shiose A, Sumimoto H. Arachidonic acid and phosphorylation synergistically induce a conformational change of $\mathrm{p} 47 \mathrm{phox}$ to activate the phagocyte NADPH oxidase. JBiol Chem (2000) 275(18):13793-801. doi:10.1074/ jbc.275.18.13793

128. Grinstein S. Imaging signal transduction during phagocytosis: phospholipids, surface charge, and electrostatic interactions. Am J Physiol Cell Physiol (2010) 299(5):C876-81. doi:10.1152/ajpcell.00342.2010

129. Yeung T, Heit B, Dubuisson JF, Fairn GD, Chiu B, Inman R, et al. Contribution of phosphatidylserine to membrane surface charge and protein targeting during phagosome maturation. J Cell Biol (2009) 185(5):917-28. doi:10.1083/ jcb. 200903020

130. Honigmann A, van den Bogaart G, Iraheta E, Risselada HJ, Milovanovic D, Mueller V, et al. Phosphatidylinositol 4,5-bisphosphate clusters act as molecular beacons for vesicle recruitment. Nat Struct Mol Biol (2013) 20(6):679-86. doi:10.1038/nsmb.2570
131. Heo WD, Inoue T, Park WS, Kim ML, Park BO, Wandless TJ, et al. PI $(3,4,5)$ P3 and PI(4,5)P2 lipids target proteins with polybasic clusters to the plasma membrane. Science (2006) 314(5804):1458-61. doi:10.1126/science.1134389

132. Kooijman EE, Chupin V, de Kruijff B, Burger KN. Modulation of membrane curvature by phosphatidic acid and lysophosphatidic acid. Traffic (2003) 4(3):162-74. doi:10.1034/j.1600-0854.2003.00086.x

133. Antonny B. Mechanisms of membrane curvature sensing. Annu Rev Biochem (2011) 80:101-23. doi:10.1146/annurev-biochem-052809-155121

134. McMahon HT, Gallop JL. Membrane curvature and mechanisms of dynamic cell membrane remodelling. Nature (2005) 438(7068):590-6. doi:10.1038/ nature 04396

135. Ciaramella A, Cavone A, Santucci MB, Garg SK, Sanarico N, Bocchino M, et al. Induction of apoptosis and release of interleukin- 1 beta by cell wall-associated $19-\mathrm{kDa}$ lipoprotein during the course of mycobacterial infection. J Infect Dis (2004) 190(6):1167-76. doi:10.1086/423850

136. Greco E, Quintiliani G, Santucci MB, Serafino A, Ciccaglione AR, Marcantonio C, et al. Janus-faced liposomes enhance antimicrobial innate immune response in Mycobacterium tuberculosis infection. Proc Natl Acad Sci U S A (2012) 109(21):E1360-8. doi:10.1073/pnas.1200484109

137. Mariotti S, Pardini M, Teloni R, Gagliardi MC, Fraziano M, Nisini R. A method permissive to fixation and permeabilization for the multiparametric analysis of apoptotic and necrotic cell phenotype by flow cytometry. Cytometry A (2017) 91(11):1115-24. doi:10.1002/cyto.a.23268

138. Santucci MB, Amicosante M, Cicconi R, Montesano C, Casarini M, Giosue S, et al. Mycobacterium tuberculosis-induced apoptosis in monocytes/macrophages: early membrane modifications and intracellular mycobacterial viability. J Infect Dis (2000) 181(4):1506-9. doi:10.1086/315371

139. Birge RB, Ucker DS. Innate apoptotic immunity: the calming touch of death. Cell Death Differ (2008) 15(7):1096-102. doi:10.1038/cdd.2008.58

140. Erwig LP, Henson PM. Immunological consequences of apoptotic cell phagocytosis. Am J Pathol (2007) 171(1):2-8. doi:10.2353/ajpath.2007.070135

141. Torchinsky MB, Garaude J, Blander JM. Infection and apoptosis as a combined inflammatory trigger. Curr Opin Immunol (2010) 22(1):55-62. doi:10.1016/j.coi.2010.01.003

142. Winau F, Weber S, Sad S, de Diego J, Hoops SL, Breiden B, et al. Apoptotic vesicles crossprime $\mathrm{CD} 8 \mathrm{~T}$ cells and protect against tuberculosis. Immunity (2006) 24(1):105-17. doi:10.1016/j.immuni.2005.12.001

143. Ichihashi T, Satoh T, Sugimoto C, Kajino K. Emulsified phosphatidylserine, simple and effective peptide carrier for induction of potent epitope-specific T cell responses. PLoS One (2013) 8(3):e60068. doi:10.1371/journal. pone. 0060068

144. Ham H, Sreelatha A, Orth K. Manipulation of host membranes by bacterial effectors. Nat Rev Microbiol (2011) 9(9):635-46. doi:10.1038/nrmicro2602

145. Pizarro-Cerda J, Charbit A, Enninga J, Lafont F, Cossart P. Manipulation of host membranes by the bacterial pathogens Listeria, Francisella, Shigella and Yersinia. Semin Cell Dev Biol (2016) 60:155-67. doi:10.1016/j. semcdb.2016.07.019

146. Weber SS, Ragaz C, Reus K, Nyfeler Y, Hilbi H. Legionella pneumophila exploits PI(4)P to anchor secreted effector proteins to the replicative vacuole. PLoS Pathog (2006) 2(5):e46. doi:10.1371/journal.ppat.0020046

147. Taus F, Santucci MB, Greco E, Morandi M, Palucci I, Mariotti S, et al. Monosodium urate crystals promote innate anti-mycobacterial immunity and improve BCG efficacy as a vaccine against tuberculosis. PLoS One (2015) 10(5):e0127279. doi:10.1371/journal.pone.0127279

148. Chua J, Deretic V. Mycobacterium tuberculosis reprograms waves of phosphatidylinositol 3-phosphate on phagosomal organelles. J Biol Chem (2004) 279(35):36982-92. doi:10.1074/jbc.M405082200

149. Wong D, Chao JD, Av-Gay Y. Mycobacterium tuberculosis-secreted phosphatases: from pathogenesis to targets for TB drug development. Trends Microbiol (2013) 21(2):100-9. doi:10.1016/j.tim.2012.09.002

150. Vergne I, Chua J, Deretic V. Tuberculosis toxin blocking phagosome maturation inhibits a novel Ca2+/calmodulin-PI3K hVPS34 cascade. J Exp Med (2003) 198(4):653-9. doi:10.1084/jem.20030527

151. Auricchio G, Garg SK, Martino A, Volpe E, Ciaramella A, De Vito $\mathrm{P}$, et al. Role of macrophage phospholipase $\mathrm{D}$ in natural and CpGinduced antimycobacterial activity. Cell Microbiol (2003) 5(12):913-20. doi:10.1046/j.1462-5822.2003.00330.x

152. Malik ZA, Thompson CR, Hashimi S, Porter B, Iyer SS, Kusner DJ. Cutting edge: Mycobacterium tuberculosis blocks $\mathrm{Ca} 2+$ signaling and 
phagosome maturation in human macrophages via specific inhibition of sphingosine kinase. J Immunol (2003) 170(6):2811-5. doi:10.4049/ jimmunol.170.6.2811

153. Greco E, De Spirito M, Papi M, Fossati M, Auricchio G, Fraziano M. CpG oligodeoxynucleotides induce Ca2+-dependent phospholipase D activity leading to phagolysosome maturation and intracellular mycobacterial growth inhibition in monocytes. Biochem Biophys Res Commun (2006) 347(4):963-9. doi:10.1016/j.bbrc.2006.06.186

154. Anes E, Kuhnel MP, Bos E, Moniz-Pereira J, Habermann A, Griffiths G. Selected lipids activate phagosome actin assembly and maturation resulting in killing of pathogenic mycobacteria. Nat Cell Biol (2003) 5(9):793-802. doi:10.1038/ncb1036

155. Garg SK, Valente E, Greco E, Santucci MB, De Spirito M, Papi M, et al. Lysophosphatidic acid enhances antimycobacterial activity both in vitro and ex vivo. Clin Immunol (2006) 121(1):23-8. doi:10.1016/j. clim.2006.06.003

156. Garg SK, Volpe E, Palmieri G, Mattei M, Galati D, Martino A, et al. Sphingosine 1-phosphate induces antimicrobial activity both in vitro and in vivo. J Infect Dis (2004) 189(11):2129-38. doi:10.1086/386286

157. Greco E, Santucci MB, Sali M, De Angelis FR, Papi M, De Spirito M, et al. Natural lysophospholipids reduce Mycobacterium tuberculosis-induced cytotoxicity and induce anti-mycobacterial activity by a phagolysosome maturation-dependent mechanism in A549 type II alveolar epithelial cells. Immunology (2010) 129(1):125-32. doi:10.1111/j.1365-2567.2009.03145.x

158. Garg SK, Santucci MB, Panitti M, Pucillo L, Bocchino M, Okajima F, et al. Does sphingosine 1-phosphate play a protective role in the course of pulmonary tuberculosis? Clin Immunol (2006) 121(3):260-4. doi:10.1016/j. clim.2006.09.002

159. Delogu G, Sali M, Rocca S, Quintiliani G, Santucci MB, Greco E, et al. Lysophosphatidic acid enhances antimycobacterial response during in vivo primary Mycobacterium tuberculosis infection. Cell Immunol (2011) 271(1):1-4. doi:10.1016/j.cellimm.2011.05.014

160. Sali M, Delogu G, Greco E, Rocca S, Colizzi V, Fadda G, et al. Exploiting immunotherapy in Mycobacterium tuberculosis-infected mice: sphingosine 1-phosphate treatment results in a protective or detrimental effect depending on the stage of infection. Int J Immunopathol Pharmacol (2009) 22(1):175-81. doi:10.1177/039463200902200120

161. Di A, Brown ME, Deriy LV, Li C, Szeto FL, Chen Y, et al. CFTR regulates phagosome acidification in macrophages and alters bactericidal activity. Nat Cell Biol (2006) 8(9):933-44. doi:10.1038/ncb1456

162. Tandrup Schmidt S, Foged C, Korsholm KS, Rades T, Christensen D. Liposome-based adjuvants for subunit vaccines: formulation strategies for subunit antigens and immunostimulators. Pharmaceutics (2016) 8(1):1-22. doi:10.3390/pharmaceutics8010007

163. Rawicz W, Olbrich KC, McIntosh T, Needham D, Evans E. Effect of chain length and unsaturation on elasticity of lipid bilayers. Biophys $J$ (2000) 79(1):328-39. doi:10.1016/S0006-3495(00)76295-3

164. Tanaka Y, Taneichi M, Kasai M, Kakiuchi T, Uchida T. Liposome-coupled antigens are internalized by antigen-presenting cells via pinocytosis and cross-presented to CD8 T cells. PLoS One (2010) 5(12):e15225. doi:10.1371/ journal.pone. 0015225

165. Christensen D, Henriksen-Lacey M, Kamath AT, Lindenstrom T, Korsholm KS, Christensen JP, et al. A cationic vaccine adjuvant based on a saturated quaternary ammonium lipid have different in vivo distribution kinetics and display a distinct $\mathrm{CD} 4 \mathrm{~T}$ cell-inducing capacity compared to its unsaturated analog. J Control Release (2012) 160(3):468-76. doi:10.1016/j. jconrel.2012.03.016

166. van Houte AJ, Snippe H, Schmitz MG, Willers JM. Characterization of immunogenic properties of haptenated liposomal model membranes in mice. V. Effect of membrane composition on humoral and cellular immunogenicity. Immunology (1981) 44(3):561-8.

167. Werninghaus K, Babiak A, Gross O, Holscher C, Dietrich H, Agger EM, et al. Adjuvanticity of a synthetic cord factor analogue for subunit Mycobacterium tuberculosis vaccination requires FcRgamma-Syk-Card9-dependent innate immune activation. JExp Med (2009) 206(1):89-97. doi:10.1084/ jem. 20081445

168. Mann JF, Shakir E, Carter KC, Mullen AB, Alexander J, Ferro VA. Lipid vesicle size of an oral influenza vaccine delivery vehicle influences the Th1/
Th2 bias in the immune response and protection against infection. Vaccine (2009) 27(27):3643-9. doi:10.1016/j.vaccine.2009.03.040

169. Brewer JM, Tetley L, Richmond J, Liew FY, Alexander J. Lipid vesicle size determines the Th1 or Th2 response to entrapped antigen. J Immunol (1998) 161(8):4000-7.

170. Manolova V, Flace A, Bauer M, Schwarz K, Saudan P, Bachmann MF. Nanoparticles target distinct dendritic cell populations according to their size. Eur J Immunol (2008) 38(5):1404-13. doi:10.1002/eji.200737984

171. Brewer JM, Pollock KG, Tetley L, Russell DG. Vesicle size influences the trafficking, processing, and presentation of antigens in lipid vesicles. J Immunol (2004) 173(10):6143-50. doi:10.4049/jimmunol.173.10.6143

172. Foged C, Arigita C, Sundblad A, Jiskoot W, Storm G, Frokjaer S. Interaction of dendritic cells with antigen-containing liposomes: effect of bilayer composition. Vaccine (2004) 22(15-16):1903-13. doi:10.1016/j.vaccine.2003.11.008

173. Henriksen-Lacey M, Christensen D, Bramwell VW, Lindenstrom T, Agger $\mathrm{EM}$, Andersen P, et al. Liposomal cationic charge and antigen adsorption are important properties for the efficient deposition of antigen at the injection site and ability of the vaccine to induce a CMI response. J Control Release (2010) 145(2):102-8. doi:10.1016/j.jconrel.2010.03.027

174. Miller CR, Bondurant B, McLean SD, McGovern KA, O’Brien DF. Liposomecell interactions in vitro: effect of liposome surface charge on the binding and endocytosis of conventional and sterically stabilized liposomes. Biochemistry (1998) 37(37):12875-83. doi:10.1021/bi980096y

175. Nakanishi T, Kunisawa J, Hayashi A, Tsutsumi Y, Kubo K, Nakagawa S, et al. Positively charged liposome functions as an efficient immunoadjuvant in inducing immune responses to soluble proteins. Biochem Biophys Res Commun (1997) 240(3):793-7. doi:10.1006/bbrc.1997.7749

176. Hussain MJ, Wilkinson A, Bramwell VW, Christensen D, Perrie Y. Th1 immune responses can be modulated by varying dimethyldioctadecylammonium and distearoyl-sn-glycero-3-phosphocholine content in liposomal adjuvants. J Pharm Pharmacol (2014) 66(3):358-66. doi:10.1111/jphp.12173

177. Hoffmann PR, Kench JA, Vondracek A, Kruk E, Daleke DL, Jordan M, et al. Interaction between phosphatidylserine and the phosphatidylserine receptor inhibits immune responses in vivo. JImmunol (2005) 174(3):1393-404. doi:10.4049/jimmunol.174.3.1393

178. Agrawal S, Agrawal A, Doughty B, Gerwitz A, Blenis J, Van Dyke T, et al. Cutting edge: different toll-like receptor agonists instruct dendritic cells to induce distinct Th responses via differential modulation of extracellular signal-regulated kinase-mitogen-activated protein kinase and c-Fos. J Immunol (2003) 171(10):4984-9. doi:10.4049/jimmunol.171.10.4984

179. Bal SM, Hortensius S, Ding Z, Jiskoot W, Bouwstra JA. Co-encapsulation of antigen and toll-like receptor ligand in cationic liposomes affects the quality of the immune response in mice after intradermal vaccination. Vaccine (2011) 29(5):1045-52. doi:10.1016/j.vaccine.2010.11.061

180. Giddam AK, Zaman M, Skwarczynski M, Toth I. Liposome-based delivery system for vaccine candidates: constructing an effective formulation. Nanomedicine (Lond) (2012) 7(12):1877-93. doi:10.2217/nnm.12.157

181. Jain V, Vyas SP, Kohli DV. Well-defined and potent liposomal hepatitis B vaccines adjuvanted with lipophilic MDP derivatives. Nanomedicine (2009) 5(3):334-44. doi:10.1016/j.nano.2008.12.004

182. Alving CR, Rao M, Steers NJ, Matyas GR, Mayorov AV. Liposomes containing lipid A: an effective, safe, generic adjuvant system for synthetic vaccines. Expert Rev Vaccines (2012) 11(6):733-44. doi:10.1586/erv.12.35

183. Richards RL, Rao M, Wassef NM, Glenn GM, Rothwell SW, Alving CR. Liposomes containing lipid A serve as an adjuvant for induction of antibody and cytotoxic T-cell responses against RTS,S malaria antigen. Infect Immun (1998) 66(6):2859-65.

184. Genito CJ, Beck Z, Phares TW, Kalle F, Limbach KJ, Stefaniak ME, et al. Liposomes containing monophosphoryl lipid A and QS-21 serve as an effective adjuvant for soluble circumsporozoite protein malaria vaccine FMP013. Vaccine (2017) 35(31):3865-74. doi:10.1016/j.vaccine.2017.05.070

185. Nagill R, Kaur S. Enhanced efficacy and immunogenicity of $78 \mathrm{kDa}$ antigen formulated in various adjuvants against murine visceral leishmaniasis. Vaccine (2010) 28(23):4002-12. doi:10.1016/j.vaccine.2010.01.015

186. Korsholm KS, Hansen J, Karlsen K, Filskov J, Mikkelsen M, Lindenstrom $\mathrm{T}$, et al. Induction of CD8+ T-cell responses against subunit antigens by the novel cationic liposomal CAF09 adjuvant. Vaccine (2014) 32(31):3927-35. doi:10.1016/j.vaccine.2014.05.050 
187. Bernstein DI, Farley N, Bravo FJ, Earwood J, McNeal M, Fairman J, et al. The adjuvant CLDC increases protection of a herpes simplex type 2 glycoprotein D vaccine in guinea pigs. Vaccine (2010) 28(21):3748-53. doi:10.1016/j. vaccine.2009.10.025

188. Morrey JD, Motter NE, Chang S, Fairman J. Breaking B and T cell tolerance using cationic lipid-DNA complexes (CLDC) as a vaccine adjuvant with hepatitis B virus (HBV) surface antigen in transgenic mice expressing HBV. Antiviral Res (2011) 90(3):227-30. doi:10.1016/j.antiviral.2011.04.006

189. Allison AG, Gregoriadis G. Liposomes as immunological adjuvants. Nature (1974) 252(5480):252. doi:10.1038/252252a0

190. Watson DS, Endsley AN, Huang L. Design considerations for liposomal vaccines: influence of formulation parameters on antibody and cell-mediated immune responses to liposome associated antigens. Vaccine (2012) 30(13):2256-72. doi:10.1016/j.vaccine.2012.01.070

191. Hale AH. H-2 antigens incorporated into phospholipid vesicles elicit specific allogeneic cytotoxic T lymphocytes. Cell Immunol (1980) 55(2):328-41. doi:10.1016/0008-8749(80)90165-3

192. Raphael L, Tom BH. In vitro induction of primary and secondary xenoimmune responses by liposomes containing human colon tumor cell antigens. Cell Immunol (1982) 71(2):224-40. doi:10.1016/0008-8749(82)90258-1

193. Ludewig B, Barchiesi F, Pericin M, Zinkernagel RM, Hengartner H, Schwendener RA. In vivo antigen loading and activation of dendritic cells via a liposomal peptide vaccine mediates protective antiviral and anti-tumour immunity. Vaccine (2000) 19(1):23-32. doi:10.1016/S0264-410X(00)00163-8

194. Engler OB, Schwendener RA, Dai WJ, Wolk B, Pichler W, Moradpour D, et al. A liposomal peptide vaccine inducing CD8+ T cells in HLA-A2.1 transgenic mice, which recognise human cells encoding hepatitis C virus (HCV) proteins. Vaccine (2004) 23(1):58-68. doi:10.1016/j.vaccine.2004. 05.009

195. Rao M, Bray M, Alving CR, Jahrling P, Matyas GR. Induction of immune responses in mice and monkeys to Ebola virus after immunization with liposome-encapsulated irradiated Ebola virus: protection in mice requires CD4(+) T cells. J Virol (2002) 76(18):9176-85. doi:10.1128/JVI.76.18.9176-9185.2002

196. Hebishima T, Yuba E, Kono K, Takeshima SN, Ito Y, Aida Y. The pH-sensitive fusogenic 3-methyl-glutarylated hyperbranched poly(glycidol)-conjugated liposome induces antigen-specific cellular and humoral immunity. Clin Vaccine Immunol (2012) 19(9):1492-8. doi:10.1128/CVI.00273-12

197. Ding Q, Chen J, Wei X, Sun W, Mai J, Yang Y, et al. RAFTsomes containing epitope-MHC-II complexes mediated CD4+ T cell activation and antigen-specific immune responses. Pharm Res (2013) 30(1):60-9. doi:10.1007/ s11095-012-0849-7

198. Gupta PN, Vyas SP. Investigation of lectinized liposomes as M-cell targeted carrier-adjuvant for mucosal immunization. Colloids Surf B Biointerfaces (2011) 82(1):118-25. doi:10.1016/j.colsurfb.2010.08.027

199. Figueiredo L, Cadete A, Goncalves LM, Corvo ML, Almeida AJ. Intranasal immunisation of mice against Streptococcus equi using positively charged nanoparticulate carrier systems. Vaccine (2012) 30(46):6551-8. doi:10.1016/j. vaccine.2012.08.050

200. Wang HW, Jiang PL, Lin SF, Lin HJ, Ou KL, Deng WP, et al. Application of galactose-modified liposomes as a potent antigen presenting cell targeted carrier for intranasal immunization. Acta Biomater (2013) 9(3):5681-8. doi:10.1016/j.actbio.2012.11.007

201. Li Z, Zhang L, Sun W, Ding Q, Hou Y, Xu Y. Archaeosomes with encapsulated antigens for oral vaccine delivery. Vaccine (2011) 29(32):5260-6. doi:10.1016/j.vaccine.2011.05.015

202. Kallert S, Zenk SF, Walther P, Grieshober M, Weil T, Stenger S. Liposomal delivery of lipoarabinomannan triggers Mycobacterium tuberculosis specific T-cells. Tuberculosis (Edinb) (2015) 95(4):452-62. doi:10.1016/j. tube.2015.04.001

203. Komori T, Nakamura T, Matsunaga I, Morita D, Hattori Y, Kuwata H, et al. A microbial glycolipid functions as a new class of target antigen for delayedtype hypersensitivity. J Biol Chem (2011) 286(19):16800-6. doi:10.1074/jbc. M110.217224

204. Morita D, Miyamoto A, Hattori Y, Komori T, Nakamura T, Igarashi T, et al. Th1-skewed tissue responses to a mycolyl glycolipid in mycobacteria-infected rhesus macaques. Biochem Biophys Res Commun (2013) 441(1):108-13. doi:10.1016/j.bbrc.2013.10.021

205. Kawasaki N, Rillahan CD, Cheng TY, Van Rhijn I, Macauley MS, Moody DB, et al. Targeted delivery of mycobacterial antigens to human dendritic cells via
Siglec-7 induces robust T cell activation. J Immunol (2014) 193(4):1560-6. doi:10.4049/jimmunol.1303278

206. Klauber TCB, Laursen JM, Zucker D, Brix S, Jensen SS, Andresen TL. Delivery of TLR7 agonist to monocytes and dendritic cells by DCIR targeted liposomes induces robust production of anti-cancer cytokines. Acta Biomater (2017) 53:367-77. doi:10.1016/j.actbio.2017.01.072

207. Schmid D, Pypaert M, Munz C. Antigen-loading compartments for major histocompatibility complex class II molecules continuously receive input from autophagosomes. Immunity (2007) 26(1):79-92. doi:10.1016/j. immuni.2006.10.018

208. Harding CV, Collins DS, Kanagawa O, Unanue ER. Liposome-encapsulated antigens engender lysosomal processing for class II MHC presentation and cytosolic processing for class I presentation. J Immunol (1991) 147(9):2860-3.

209. Joffre OP, Segura E, Savina A, Amigorena S. Cross-presentation by dendritic cells. Nat Rev Immunol (2012) 12(8):557-69. doi:10.1038/nri3254

210. Zehner M, Marschall AL, Bos E, Schloetel JG, Kreer C, Fehrenschild D, et al. The translocon protein Sec61 mediates antigen transport from endosomes in the cytosol for cross-presentation to CD8(+) T cells. Immunity (2015) 42(5):850-63. doi:10.1016/j.immuni.2015.04.008

211. Nunes-Hasler P, Demaurex N. The ER phagosome connection in the era of membrane contact sites. Biochim Biophys Acta (2017) 1864(9):1513-24. doi:10.1016/j.bbamcr.2017.04.007

212. Gao J, Ochyl LJ, Yang E, Moon JJ. Cationic liposomes promote antigen cross-presentation in dendritic cells by alkalizing the lysosomal $\mathrm{pH}$ and limiting the degradation of antigens. Int J Nanomedicine (2017) 12:1251-64. doi:10.2147/IJN.S125866

213. Liu L, Ma P, Wang H, Zhang C, Sun H, Wang C, et al. Immune responses to vaccines delivered by encapsulation into and/or adsorption onto cationic lipid-PLGA hybrid nanoparticles. J Control Release (2016) 225:230-9. doi:10.1016/j.jconrel.2016.01.050

214. Moore NM, Sheppard CL, Barbour TR, Sakiyama-Elbert SE. The effect of endosomal escape peptides on in vitro gene delivery of polyethylene glycol-based vehicles. J Gene Med (2008) 10(10):1134-49. doi:10.1002/jgm.1234

215. Miura N, Akita H, Tateshita N, Nakamura T, Harashima H. Modifying antigen-encapsulating liposomes with KALA facilitates MHC class I antigen presentation and enhances anti-tumor effects. Mol Ther (2017) 25(4):1003-13. doi:10.1016/j.ymthe.2017.01.020

216. Reddy R, Zhou F, Huang L, Carbone F, Bevan M, Rouse BT. pH sensitive liposomes provide an efficient means of sensitizing target cells to class I restricted CTL recognition of a soluble protein. J Immunol Methods (1991) 141(2):157-63. doi:10.1016/0022-1759(91)90142-3

217. Barnier-Quer C, Elsharkawy A, Romeijn S, Kros A, Jiskoot W. Adjuvant effect of cationic liposomes for subunit influenza vaccine: influence of antigen loading method, cholesterol and immune modulators. Pharmaceutics (2013) 5(3):392-410. doi:10.3390/pharmaceutics5030392

218. Takagi A, Kobayashi N, Taneichi M, Uchida T, Akatsuka T. Coupling to the surface of liposomes alters the immunogenicity of hepatitis $\mathrm{C}$ virus-derived peptides and confers sterile immunity. Biochem Biophys Res Commun (2013) 430(1):183-9. doi:10.1016/j.bbrc.2012.11.028

219. Matsui M, Kohyama S, Suda T, Yokoyama S, Mori M, Kobayashi A, et al. A CTL-based liposomal vaccine capable of inducing protection against heterosubtypic influenza viruses in HLA-A*0201 transgenic mice. Biochem Biophys Res Commun (2010) 391(3):1494-9. doi:10.1016/j.bbrc.2009. 12.100

220. Nagata T, Toyota T, Ishigaki H, Ichihashi T, Kajino K, Kashima Y, et al. Peptides coupled to the surface of a kind of liposome protect infection of influenza viruses. Vaccine (2007) 25(26):4914-21. doi:10.1016/j.vaccine.2007.04.010

221. Naito S, Horino A, Nakayama M, Nakano Y, Nagai T, Mizuguchi J, et al. Ovalbumin-liposome conjugate induces IgG but not IgE antibody production. Int Arch Allergy Immunol (1996) 109(3):223-8. doi:10.1159/000237241

222. Taneichi M, Ishida H, Kajino K, Ogasawara K, Tanaka Y, Kasai M, et al. Antigen chemically coupled to the surface of liposomes are cross-presented to CD8+ T cells and induce potent antitumor immunity. J Immunol (2006) 177(4):2324-30. doi:10.4049/jimmunol.177.4.2324

223. Masek J, Bartheldyova E, Turanek-Knotigova P, Skrabalova M, Korvasova Z, Plockova J, et al. Metallochelating liposomes with associated lipophilised norAbuMDP as biocompatible platform for construction of vaccines with recombinant His-tagged antigens: preparation, structural study and 
immune response towards rHsp90. J Control Release (2011) 151(2):193-201. doi:10.1016/j.jconrel.2011.01.016

224. Watson DS, Platt VM, Cao L, Venditto VJ, Szoka FC Jr. Antibody response to polyhistidine-tagged peptide and protein antigens attached to liposomes via lipid-linked nitrilotriacetic acid in mice. Clin Vaccine Immunol (2011) 18(2):289-97. doi:10.1128/CVI.00425-10

225. Matyas GR, Mayorov AV, Rice KC, Jacobson AE, Cheng K, Iyer MR, et al. Liposomes containing monophosphoryl lipid A: a potent adjuvant system for inducing antibodies to heroin hapten analogs. Vaccine (2013) 31(26):2804-10. doi:10.1016/j.vaccine.2013.04.027

226. Brito LA, Kommareddy S, Maione D, Uematsu Y, Giovani C, Berlanda Scorza F, et al. Self-amplifying mRNA vaccines. Adv Genet (2015) 89:179-233. doi:10.1016/bs.adgen.2014.10.005

227. Pardi N, Weissman D. Nucleoside modified mRNA vaccines for infectious diseases. Methods Mol Biol (2017) 1499:109-21. doi:10.1007/978-1-4939-6481-9_6

228. Desmet CJ, Ishii KJ. Nucleic acid sensing at the interface between innate and adaptive immunity in vaccination. Nat Rev Immunol (2012) 12(7):479-91. doi:10.1038/nri3247

229. Kariko K, Ni H, Capodici J, Lamphier M, Weissman D. mRNA is an endogenous ligand for toll-like receptor 3. J Biol Chem (2004) 279(13):12542-50. doi:10.1074/jbc.M310175200

230. Richner JM, Himansu S, Dowd KA, Butler SL, Salazar V, Fox JM, et al. Modified mRNA vaccines protect against Zika virus infection. Cell (2017) 168(6):1114-25.e10. doi:10.1016/j.cell.2017.02.017

231. Chen S, Tam YYC, Lin PJC, Sung MMH, Tam YK, Cullis PR. Influence of particle size on the in vivo potency of lipid nanoparticle formulations of siRNA. J Control Release (2016) 235:236-44. doi:10.1016/j.jconrel.2016. 05.059

232. Hekele A, Bertholet S, Archer J, Gibson DG, Palladino G, Brito LA, et al. Rapidly produced $\operatorname{SAM}((\mathrm{R}))$ vaccine against $\mathrm{H7N} 9$ influenza is immunogenic in mice. Emerg Microbes Infect (2013) 2(8):e52. doi:10.1038/emi.2013.54

233. Liang F, Lindgren G, Lin A, Thompson EA, Ols S, Rohss J, et al. Efficient targeting and activation of antigen-presenting cells in vivo after modified mRNA vaccine administration in rhesus macaques. Mol Ther (2017) 25(12):2635-47. doi:10.1016/j.ymthe.2017.08.006

234. Bogers WM, Oostermeijer H, Mooij P, Koopman G, Verschoor EJ, Davis $\mathrm{D}$, et al. Potent immune responses in rhesus macaques induced by nonviral delivery of a self-amplifying RNA vaccine expressing HIV type 1 envelope with a cationic nanoemulsion. J Infect Dis (2015) 211(6):947-55. doi:10.1093/ infdis/jiu522

235. Zumla A, Rao M, Wallis RS, Kaufmann SH, Rustomjee R, Mwaba P, et al. Host-directed therapies for infectious diseases: current status, recent progress, and future prospects. Lancet Infect Dis (2016) 16(4):e47-63. doi:10.1016/ S1473-3099(16)00078-5

236. Zumla A, Memish ZA, Maeurer M, Bates M, Mwaba P, Al-Tawfiq JA, et al. Emerging novel and antimicrobial-resistant respiratory tract infections: new drug development and therapeutic options. Lancet Infect Dis (2014) 14(11):1136-49. doi:10.1016/S1473-3099(14)70828-X

237. Douer D. Efficacy and safety of vincristine sulfate liposome injection in the treatment of adult acute lymphocytic leukemia. Oncologist (2016) 21(7):840-7. doi:10.1634/theoncologist.2015-0391

238. Sarantis H, Grinstein S. Subversion of phagocytosis for pathogen survival. Cell Host Microbe (2012) 12(4):419-31. doi:10.1016/j.chom.2012. 09.001

239. Mariotti S, Pardini M, Gagliardi MC, Teloni R, Giannoni F, Fraziano M, et al. Dormant Mycobacterium tuberculosis fails to block phagosome maturation and shows unexpected capacity to stimulate specific human T lymphocytes. J Immunol (2013) 191(1):274-82. doi:10.4049/jimmunol.1202900

240. Goldberg MF, Saini NK, Porcelli SA. Evasion of innate and adaptive immunity by Mycobacterium tuberculosis. Microbiol Spectr (2014) 2(5):1-24. doi:10.1128/microbiolspec.MGM2-0005-2013

241. Liu CH, Liu H, Ge B. Innate immunity in tuberculosis: host defense vs pathogen evasion. Cell Mol Immunol (2017) 14(12):963-75. doi:10.1038/ cmi.2017.88

Conflict of Interest Statement: All the authors declare no business relationship that might lead to a conflict of interest.

Copyright (c) 2018 Nisini, Poerio, Mariotti, De Santis and Fraziano. This is an open-access article distributed under the terms of the Creative Commons Attribution License (CC BY). The use, distribution or reproduction in other forums is permitted, provided the original author(s) and the copyright owner are credited and that the original publication in this journal is cited, in accordance with accepted academic practice. No use, distribution or reproduction is permitted which does not comply with these terms. 